\title{
Wein, Weib und Gesang. A propósito de tres apliques de bronce arcaicos entre la Península Ibérica y Baleares
}

\section{Wein, Weib und Gesang. Three archaic bronze appliques between Iberian Peninsula and Balearic Islands}

\author{
Giacomo Bardelli \\ Römisch-Germanisches Zentralmuseum Mainz \\ Dr. Raimon Graells i Fabregat \\ Römisch-Germanisches Zentralmuseum Mainz \\ Forschungsstipendiat der Alexander von Humboldt-Stiftung
}

\section{RESUMEN}

El nuevo estudio de tres figuras de bronce de tipo etrusco e itálico permite reconsiderar el dossier de la vajilla metálica importada en el Mediterráneo occidental. En primer lugar, una completa descripción de cada figura autoriza consideraciones acerca de la procedencia así como su correcta función original.

En segundo lugar, se ofrece una revisión de la vajilla metálica etrusca e itálica recuperada en la Península en la que se incluyen nuevos hallazgos. Este catálogo organiza los distintos tipos de importaciones de manera exhaustiva.

Finalmente, se contextualizan los tres fragmentos examinados en la primera parte, destacándose respecto a las importaciones estándar. Como resultado, para dos de las tres piezas, la procedencia de contextos arqueológicos del mediterráneo occidental es difícil de aceptar.

\section{SUMMARY}

A new study of three small bronze figures of Etruscan and Italic manufacture gives the opportunity to reconsider the dossier of bronze vessels imported in the Western Mediterranean Area. Firstly, a thorough description of each figure allows to determinate their provenance and to make new hypothesis about their correct placement. Secondly, a review of Etruscan and Italic vessels found on the Peninsula, including some new findings, is presented. This review shows clearly specific tendencies concerning the import of archaic vessels. Finally, the presence of these objects is related to the examined figures, thus giving the chance to explain their outstanding nature in

* Queremos agradecer los comentarios y colaboración del Sr. J. Jiménez-Gadea (Museo de Ávila), Prof. Dr. A. Naso (Universität Innsbruck), Prof. M. Harari (Università degli Studi di Pavia), Dr. J. Gran-Aymerich (CNRS UMR-8546), Dr. J. Swaddling (British Museum), Prof. R. Corzo (U. Sevi1la), Dra. M. D. López, M. Santos (MAC-Empuries) y J. M. Alonso de la Sierra (Museo Cádiz). comparison to standard imports. Therefore, a provenance from archaeological contexts, at least for two of them, is hardly acceptable.

PALABRAS CLAVE: Aplique, vajilla metálica, cista, Etruria, Campania, banquete.

KEY WORDS: Applique, metallic vessel, cista, Etruria, Campania, Banquet.

\section{INTRODUCCIÓN*}

En los últimos años, especialmente a partir del Congreso de Barcelona de 1990, la atención dedicada a la presencia de materiales de procedencia etrusca e itálica en la Península Ibérica ha aumentado considerablemente. De este modo, a las actas del congreso de Barcelona se han añadido estudios dedicados a materiales y hallazgos particulares (Roldán 19951996; Botto y Vives-Ferrándiz 2006; Bruni 2007; Vives-Ferrándiz 2007; Graells 2008b, 2010) y panorámicas más amplias, fruto de reflexiones de mayor alcance. Normalmente el interés ha sido hacia las relaciones entre Oriente y Occidente del Mediterráneo antiguo, a veces con valoración del rol desarrollado como intermediario por parte de las culturas de la Península Itálica, particularmente Etruria. Entre estos trabajos destacan las síntesis catalanas, por un lado (Aquilué et alii 2006; Graells 2010; Sanmartí, Asensio y Martín 2006) y las visiones del conjunto peninsular, por otro (Llobregat 1982; Almagro-Gorbea 1992; Botto y Vives-Ferrándiz 2006; Graells 2010 y e.p). 
El estado actual de conocimiento, a falta de una síntesis profunda y completa sobre el argumento, permite delinear con cierta precisión un cuadro de los testimonios etrusco-itálicos recuperados en la Península Ibérica. Ello contribuye a la reconstrucción del flujo y la distribución de los materiales de manera diacrónica, desde la Primera Edad del Hierro. A tal efecto, el análisis de los materiales permite identi-ficar las fases y frecuencia de recepción de las importaciones, siguiendo rutas bien delimitadas en el Mediterráneo centro-occidental y a lo largo del Golfo de León ${ }^{1}$, que se estructuran alrededor de unos grupos tipológicos y funcionales concretos. Además, el catálogo de hallazgos muestra de manera frecuente casos de difícil interpretación ${ }^{2}$, de los que aquí analizamos tres.

La ausencia de contexto, la distancia respecto a la norma definida por las tipologías realizadas con los materiales contextualizados y la posición anómala en áreas donde la presencia etrusca e itálica arcaica es ausente o muy débil son los argumentos que obligan a considerar algunos casos de manera particular. Apliques de bronce figurados, únicos y en buen estado de conservación, son conocidos únicamente a partir de hallazgos extraordinarios que, de aceptarlos, convierten en norma lo que debería ser excepción.

Más problemático es, si cabe, cuando estos objetos han sido vendidos después de su hallazgo en una zona imprecisa, a veces indemostrable o fuera de toda lógica con datos arqueológicos, como ocurre, por ejemplo, tanto con la figura de Royos, Capilla, Llano de la Consolación, Raso o Rafal de Toro que seguidamente comentaremos. Deberíamos pensar, pues, que se trata de una estrategia comercial y, consecuentemente, en un falseamiento de la documentación arqueológica. Otros casos, también descontextualizados, en cambio, pueden responder a hallazgos casuales, también excepcionales, pero explicables dentro de una lógica del tipo de importación o por la falta de identificación de la pieza, al menos para propósitos comerciales. Recordemos el fragmento de asa de enócoe etrusco de Cuenca, identificado como fragmento de figura romana y que procede de un área donde la presencia de vasos metálicos etruscos es conocida, además de corresponder a un tipo presente ya en la Península (Graells 2008b). De manera opuesta, identificado por el contexto, se ha rechazado la espada de tipo Terni, hasta hace poco considerada como el

${ }^{1}$ Vid. Catálogo Les étrusques en Languedoc (2002) y actas del XXIV Convegno di Studi Etruschi e Italici: Da Genova ad Ampurias (2006).

${ }^{2}$ F. Croissant y P. Rouillard los definían elegantemente como “...doublement isolées. Non seulement leur répartition paraît aléatoire dans le temps comme dans l'espace..." (1997, 59). testimonio más antiguo de contactos entre etruscos y la Península Ibérica. Recientemente ha sido reexaminada por parte de D. Brandherm (2007, 1, n. 4) que ha destacado la procedencia dudosa y ha reconstruido el recorrido anticuario argumentándolo en base a la incoherente presencia tanto en relación al contexto cultural local como a su encaje en los mapas de distribución y las dinámicas documentadas arqueológicamente. De este modo, es importante recordar como a menudo el estudio de los materiales de colecciones y hallazgos antiguos tiene el problema de la falta de documentación, que impide identificar la exacta procedencia de los materiales. Pocos son los casos que permiten este tipo de estudios y hoy es necesario revisarlos para aprovechar al máximo los datos del registro y corregir informaciones para poder incluirlos en un discurso histórico-arqueológico moderno ${ }^{3}$.

A este propósito, la revisión del dossier de materiales arcaicos de la Península Ibérica, en particular los objetos metálicos de bronce, ofrece la ocasión para reconsiderar algunas producciones del artesanado toréutico hasta ahora estudiado de manera parcial o incompleta, no sin interés a mayor escala, particularmente en relación al panorama de las importaciones etruscas e itálicas a caballo entre el siglo vi y v a.C.

En esta particular problemática, otra cuestión importante es la relativa a las figuritas de bronce que aparecen en algunos lugares de la Península y las Baleares. La de Raso de Candeleda (Ávila), que podría corresponder a un comensal reclinado, por ejemplo, se considera etrusca en muchas publicaciones. Por otro lado, el sileno de Capilla (Badajoz) ha sido relacionado por algunos autores con influjos magno-griegos, otros con aires etrusquizantes y, aún, otros con talleres locales. Ante este panorama, en las páginas que siguen, consideramos tres pequeños apliques, que con toda probabilidad habrían estado fijadas originalmente sobre objetos de mayores dimensiones, de los que no nos han perdurado restos y muchas veces se ha planteado que fueran elementos de vajilla metálica, es decir, se han interpretado como asas, remates de asas, etc.

Los tres apliques que se consideran muestran figuras de personajes humanos, no mitológicos, que han sido interpretados, algunos recientemente incluso, de manera imprecisa. El examen reconsidera la función original y su correcta posición dentro del repertorio

${ }^{3}$ Caso de la revisión de los bronces de la Hispania Graeca de A. García y Bellido (1948), anotación hecha ya por R. Asensi (1991); las colecciones del MAN-Madrid (especialmente la colección Salamanca, con gran cantidad de materiales de procedencia italiana); colecciones del MAC-Barcelona, muchas de ellas con materiales del entorno de Empúries y otros de procedencia Balear; etc. 
material — tipológica y cronológicamente - y discute su encaje en el contexto peninsular. Quedan fuera del grupo el Sileno de Capilla (Olmos 1977 y 2000a), el sátiro itifálico del Llano de la Consolación (Olmos 2000b) y el centauro de Royos (Olmos 1983; Rodero 2000), que se añadirán al discurso en las conclusiones, para presentar una valoración conjunta.

Así, el dossier nos interesa por triple motivo: primero, iconográfica y temáticamente los tres fragmentos considerados se relacionan con un origen itálico; segundo, son partes independientes que pertenecieron a grandes objetos metálicos; tercero, su filiación tipo-cronológica es homogénea en el momento de tránsito entre el siglo vi y v a.C.

\section{EL JOVEN RECOSTADO DE LA ALGAIDA}

La pequeña figura de bronce (alto $40 \mathrm{~mm}$, largo $60 \mathrm{~mm})^{4}$, realizada por fusión plena, fue recuperada durante las campañas de excavación llevadas a cabo en el santuario púnico de Monte Algaida (cerca de Sanlúcar de Barrameda) entre 1978 y 1984 (BlancoFreijeiro y Corzo 1983, 124; Corzo 1991: 403, Tav. VI). Las pocas noticias publicadas describen un área boscosa situada sobre un terreno en gran parte arenoso que, además de haber favorecido el hallazgo esporádico de materiales, a menudo presa de excavaciones clandestinas, ha dificultado las observaciones de carácter estratigráfico del lugar. Actualmente no se dispone de la información acerca de la exacta posición de hallazgo de la figura, que ha sido genéricamente incluida entre los materiales recuperados en la fase más antigua del santuario (considerado en uso a partir de inicios del siglo v a.C.) (Corzo 2000: 149-151).

La figura que aquí interesa representa a un joven en posición recostada, reposando sobre el muslo izquierdo y con las dos piernas flexionadas asimétricamente, la derecha hacia arriba y la izquierda orientada hacia el espectador. Abiertas de esta manera, ponen en evidencia el sexo, particularmente pronunciado (Fig.1, fig. 2 y fig. 3 ).

El torso, de apariencia rígida y con escaso detalle anatómico, está representado frontalmente y se extiende progresivamente de la cintura a los hombros. El brazo izquierdo está flexionado, dirigiendo la mano hacia la cabeza donde, en su proximidad, se cierra. La mano izquierda no está en contacto directo con

${ }^{4}$ Estas medidas responden a la ficha de catálogo del Museo de Cádiz. En cambio, R. Corzo presentó unas medidas ligeramente distintas $(40 \mathrm{~mm} \times 70 \mathrm{~mm})($ Corzo 1991, 403).

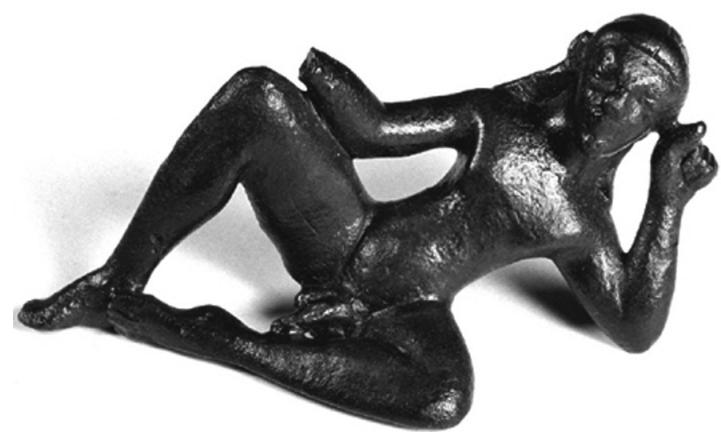

Figura 1. Vista frontal de la figura del joven del Santuario de la Algaida (Foto: Museo de Cádiz).

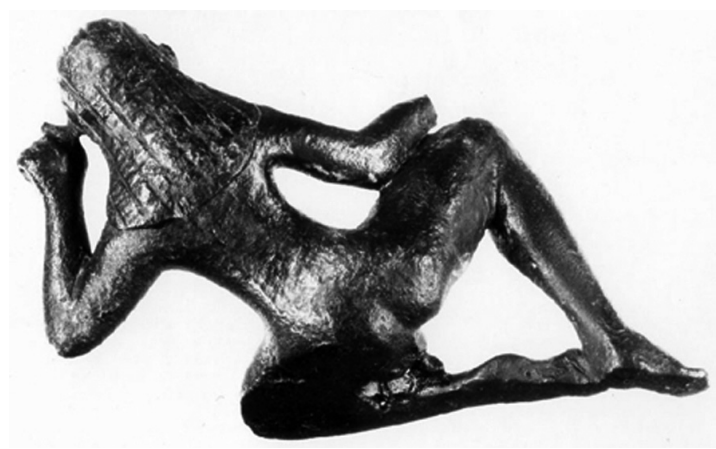

Figura 2. Vista posterior de la figura del joven del Santuario de la Algaida (Foto: Museo de Cádiz).

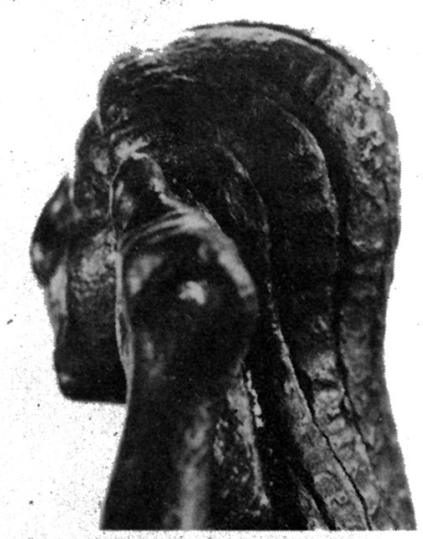

Figura 3. Vista de detalle, lateral, de la cabeza y la mano izquierda de la figura del joven del Santuario de la Algaida (Corzo 1991: 408, Fig. 6).

la cabeza sino unida a ella a través de un punto de bronce para el que nos inclinamos a pensar que corresponde a un resto de fusión. Aun así, una propuesta alternativa permite pensar en que estaría cogiendo bien un objeto, bien una trenza o quizás, únicamente, reflejando una posición cómoda sobre la que apo- 


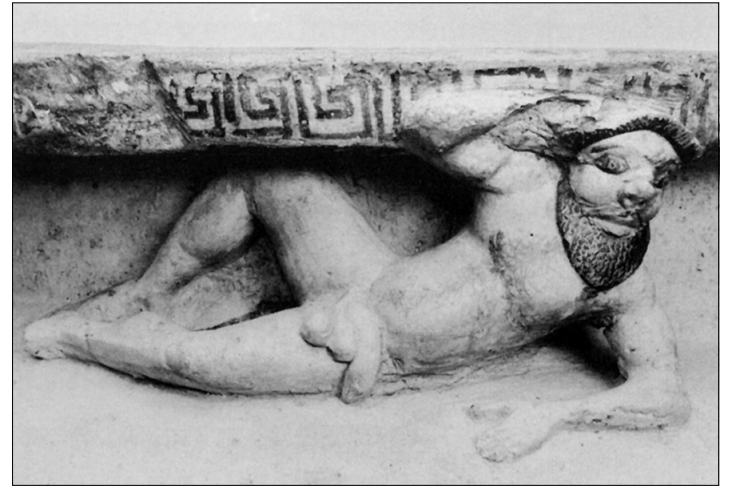

Figura 4. Detalle de la decoración plástica de la crátera corintia del Museo nacional de Copenhague (CHR VIII.940) con representación de sátiro itifálico (Barr-Sharrar 2008: 85, Fig. 77.b).

yar la cabeza sobre el brazo, que sin el resto de fusión, daría una sensación de movimiento. El brazo derecho, en cambio, aparece extendido, hecho que permite hacer reposar el antebrazo sobre el muslo derecho. La mano derecha, lamentablemente, falta.

La cabeza está soportada por un cuello macizo y está decorada por una cabellera de kourós esquemática, corta y recta sobre la frente y con largas trenzas, indicadas mediante pequeños trazos horizontales, que caen por la nuca hasta un poco más allá de las clavículas. La cara, frontal y de forma oval, es hoy prácticamente ilegible a causa del desgaste de la superficie del bronce, de manera que las observaciones estilísticas que puedan proponerse son casi por intuición.

La técnica de fabricación, mediante fusión plena, no parece haber sido completada por una decoración con punzones, tal y como parece indicar la ausencia de marcas. Únicamente el detalle de las trenzas sobre la parte posterior da la impresión de haber sido realizado sobre el modelo antes de la fusión. A pesar de no conocerse un paralelo estricto para esta figura, es clara la influencia de carácter jónico en la forma del busto y en la anatomía, donde la musculatura y las articulaciones se muestran diluidas, en representación sutil, así como la forma oval de la faz. El tratamiento de los cabellos es el típico de los pequeños bronces representando kouro $i^{5}$ y el grosor de los muslos y la sutil cintura recuerdan, quizás, a algunas asas antropomorfas de la vajilla metálica. La falta de datos de contexto sugiere una datación, basada en observaciones estilísticas, hacia finales del 235.

${ }^{5}$ Por ejemplo Richardson 1983, 116, N. 9, Tav. 64, Fig siglo vi a.C. Desde el punto de vista iconográfico, en cambio, la figura se enmarca en una iconografía típica del banquete, ampliamente documentada a partir del arcaísmo sobre diversas clases de representaciones, en las que las piernas no están extendidas paralelamente sino que una de ellas, normalmente la derecha, está flexionada, con la rodilla hacia arriba (Dentzer 1982: 80, nota 51; 219). La falta de la mano derecha impide afirmar, con absoluta certeza, que el joven esté representado en actitud de simposiasta, ante la imposibilidad de demostrar el verosímil sustento de una copa u otro vaso.

Pero el aspecto más sorprendente de la figura es la desnudez explícita con la que se muestra el joven. Revisando la iconografía de los banquetantes, se observa como la desnudez es, en efecto, una característica prácticamente exclusiva de silenos ${ }^{6}$. Un ejemplo de ello, con posición similar en la que el sexo aparece expuesto como en el ejemplar de la Algaida, se documenta en el Sileno plástico aplicado sobre el cuello de la crátera de columnas corintia del Museo Nacional de Copenhague (N. Inv. CHR.VIII.940, CVA Copenhaguen (3), Tav. 125) (Fig. 4). A tal efecto, si los silenos se presentan, en este contexto, desnudos, la regla para los humanos es la contraposición mediante una participación vestidos. En este sentido tenemos que considerar la afirmación de M. Micozzi (1993: 8), según la que la desnudez no sería una característica de la iconografía del banquete $^{7}$. Existen también en la pequeña toréutica algunas excepciones entre las que destaca una figura masculina de Samos, en la Antikensammlung de Berlín (aunque de interpretación controvertida, vid. Bieg 2002: 136, Fig. 188; 175, N. SY 9), una figura de la colección Borowsky (Kunze 2007, 84, N. A 19) y las tres figuras recostadas sobre el anillo inferior

\footnotetext{
${ }^{6} \mathrm{Se}$ vean, por ejemplo, las pequeñas figuras de sileno en bronce, griegas y magno-griegas, recopiladas por Bieg (2002: 141-144 y 178-179). Muchos silenos de bronce en posición recostada han sido documentados en Etruria (para ejemplos y catálogo parcial v. Riis 1998: 66-67, notas 140-142). En particular, dos casos con posición similar a la de la representación de la Algaida se documentan en las figuras de sátiro de la colección Schimmel (Muscarella 1974, N. 88) y del Museo de Saint-Louis (Mitten-Doeringer 1967: 98, N. 95).

${ }^{7}$ Representaciones de figuras relacionadas con el banquete, aunque no directamente participantes en el simposio o no representadas dentro de escenas de banquete, se identifican sobre la pintura vascular. Vid. por ejemplo CVA London (4), Tav. 70, 8b (ánfora fn); CVA Fogg Museum and Gallatin, Tav. 60, 11 (lekythos técnica Six); CVA Hannover (1), Tav. 17, 4 (ánfora fn); CVA Adria (1), Tav. 3, 5 (kylix); CVA Amsterdam (1), Tav. 22, 5 (kylix).

Sobre pintura funeraria etrusca, el motivo también aparece, vid. por ejemplo dos figuras que decoran el tímpano de la Tomba del Triclinio (Tarquinia, Viterbo) (Weber-Lehmann 1985: 28, Tav. 20.3 y 21.3)
} 
del trípode a verghette del Museo de Karlsruhe (Jurgeit 1999: 259-262, N. 416). En cualquier caso, la ausencia de cualquier atributo definitorio hace difícil explicar a quien representa el joven del santuario de La Algaida y porqué aparece desnudo.

Por otro lado, es posible hacer algunas hipótesis acerca de la posición original de la pieza. Desde su hallazgo fue interpretada como un aplique de un objeto no conservado y, en particular, se propuso su atribución como fragmento de cista de bronce ${ }^{8}$. El fragmento fue posteriormente publicado por P.J. Riis, que lo incluyó dentro de su estudio sobre la toréutica etrusca del tardo-arcaísmo (Riis 1998: 60 y 62, Fig. 57). Riis propuso relacionar el bronce de la Algaida con otras pequeñas figuras que originariamente habrían sido situadas como ornamentación en los anillos inferiores de trípodes a verghette de producción vulcente (Riis 1998: 60) ${ }^{9}$. Los paralelos sugeridos eran las figuras, ya citadas, situadas sobre el trípode del Museo de Karlsruhe ${ }^{10}$. Pero los bronces de Karlsruhe, muestran aún un tratamiento anatómico mucho más desarticulado que el ejemplar de la Algaida, además de que las dimensiones son ligeramente inferiores (cada uno de ellos mide $30 \mathrm{~mm}$ de alto por $40 \mathrm{~mm}$ de largo). La diferencia en las dimensiones, aunque mínima, es significativa ya que el espacio sobre los anillos inferiores de los trípodes conocidos es limitado para encajar figuras de dimensiones análogas a las de las figuras de Karlsruhe pero no superiores ${ }^{11}$. Además, como señaló R. Corzo (1991:

\footnotetext{
${ }^{8}$ Corzo Sánchez 1991: 403-404. Tal interpretación fue relacionada a la presencia, entre los hallazgos, de pies de cista de fábrica etrusca, prácticamente sin argumentación ulterior. Una aproximación a las dos piezas (Corzo 1991: 409, Fig. 67) permite dudar sobre la atribución como pie de cista de una de ellas y, para la segunda, una proximidad a las series de Praeneste, como permiten proponer el detalle de las alas y de la pluma central. En cambio, a título de comentario de algunos detalles divergentes, la posición de la garra resulta ligeramente más regular y respetuosa con un ángulo de $90^{\circ}$ respecto al resto de la pieza de lo que se observa en las series prenestinas. Esta diferencia no debería invalidar la filiación de la pieza a dicho taller.

${ }^{9}$ Sobre los trípodes a verghette v. Neugebauer 1943: 206233; Riis 1998.

${ }^{10}$ De la misma opinión de Riis son Colonna 2006:14; Botto y Vives-Ferrándiz 2006: 125; Gran-Aymerich 2010: 18.

${ }^{11}$ Se vean, por ejemplo, los silenos que decoran el trípode N. inv. 12110 del Museo del Vaticano (Riis 1998: 65-66) y n. 588 del British Museum de Londres. Los silenos del trípode del British Museum miden, respectivamente, 27,5 $\mathrm{mm}$ x 41 mm y 26,5 x 44 mm (Haynes 1985: 264-265, n. 53). También pueden valorarse los dos silenos, también verosímilmente atribuibles a la decoración de una trípode, conservados en Berlín (SMPK, N. 1490p y N. 1490q, respectivamente 30 x $42 \mathrm{~mm}$ y 31 x $45 \mathrm{~mm}$ (datos obtenidos del catálogo fotográfico online Antike Bronzen in Berlin; también Riis 1998, 6667, notas 141-142).
}

403), la parte inferior de la pierna izquierda del joven estaría adaptada a una superficie ligeramente convexa, imposibilitando de esta manera su colocación sobre un anillo de trípode. Estos elementos - los anillos inferiores-, exclusivos de los trípodes tardo-arcaicos de producción vulcente, presentan siempre una superficie perfectamente plana ${ }^{12}$.

De esta manera, la propuesta de identificar la pieza como fragmento de trípode, avanzada por P. J. Riis y recientemente retomada por G. Colonna, que la ha ampliado imaginando la llegada a la Algaida de un émporos etrusco que ofrecería el trípode, queda invalidada. Si bien históricamente aceptable resulta incongruente con la identificación real de la pieza, para la que resulta más convincente la idea original, hoy alternativa, que identifica la aplicación de la figura a una tapadera de vaso ${ }^{13}$.

\section{UNA BANQUETANTE DEL RASO DE CANDELEDA}

En 1953 fue donada al Museo de Ávila la colección de Fulgencio Serrano Chozas, estudioso local que entre 1933 y 1936 efectuó algunos hallazgos en la zona del Raso (cerca de Candeleda) (Molinero-Pérez 1958, 175). Entre los materiales se incluyó una pequeña figura de bronce, realizada por fusión plena, procedente, según palabras del mismo Serrano Chozas, del sitio llamado La Cerca, en el año 1933.

La figura (Molinero-Pérez 1958; Fernández 1972: 274-275; 1991; Blázquez 1975: 199; Almagro-Gorbea 1977: 253, 256 y 505; Olmos y Picazo 1979: 189; Mariné 2011, 24, N. Cat. 12), representa un personaje femenino recostado sobre el lado izquierdo (Fig. 5 y fig.6). Las piernas se presentan paralelas, extendidas con una ligera flexión, mientras que el busto está suavemente alzado. Los pies son pequeños y fusiformes. El brazo izquierdo se apoya en el mis-

\footnotetext{
12 Únicamente el trípode conservado en el Museo de l'Ermitage podría suponer una excepción al presentar un anillo de sección circular que aparece, a diferencia del resto, decorado por figuras de aves (Riis 1998: 53-55, Fig. 47).

${ }^{13}$ A tal efecto, vale la pena recordar un lebes de bronce de la colección Ortiz (1996, N. 194), atribuido, no sin reservas, a una procedencia capuana. Dicho vaso presenta sobre su tapadera una figura recostada aplicada que recuerda al ejemplar andaluz tanto por las dimensiones (alto 41,6 $\mathrm{mm}$, largo 71,7 $\mathrm{mm}$ ) como por la representación. Cabe decir que este vaso es un unicum en comparación a las series capuanas recopiladas por R. Benassai (1995). La morfología esférica y las diferencias de pátina entre el cuerpo y el aplique obligan a ciertas precauciones antes de la automática aceptación de la interpretación y originalidad de la pieza.
} 


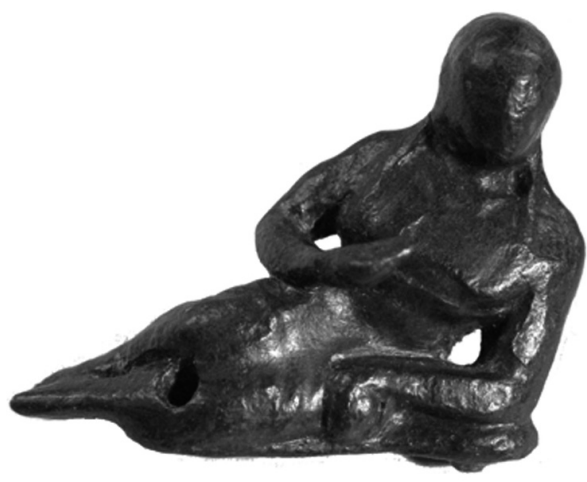

Figura 5. Vista frontal de la figura de la muchacha de Raso de Candeleda (Foto: Museo de Ávila).

mo nivel que el costado de la figura y soporta el peso del torso. Finalmente, el brazo derecho está recogido a la altura del pecho. Ambas manos parecen coger un objeto, quizás un fruto.

La cabeza, girada hacia el espectador, se conserva en precario estado y la lectura de la faz resulta imposible. Aún así, se reconoce una cobertura de la cabeza que representaría originalmente un tejido - un tutulus - y dos trenzas que caen sobre el pecho. La figura se presenta vestida con una larga túnica, que termina poco después de los tobillos. A pesar del estado de conservación, la superficie de la pieza aparece de forma regular, mostrando una pátina verde uniforme. En la parte inferior se observa una pequeña placa oblonga, fundida conjuntamente al costado de la representación y al antebrazo izquierdo. Esta placa presenta dos agujeros —uno de los cuales conserva aún un pequeño vástago, supuestamente, de fijación - que se relacionan directamente como elementos estructurales imprescindibles para la

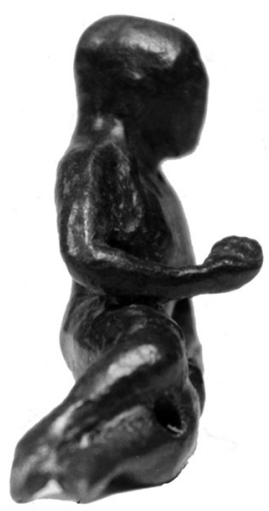

Figura 6. Vista lateral de la figura de la muchacha de Raso de Candeleda (Foto: Museo de Ávila).

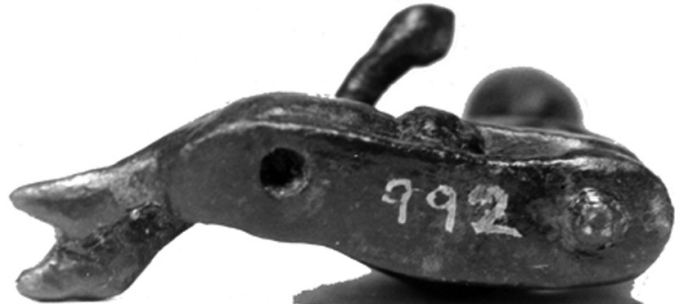

Figura 7. Vista inferior de la figura de la muchacha de Raso de Candeleda (Foto: Museo de Ávila).

aplicación de la figura a otro soporte (Fig. 7). Uno de los agujeros, el que no conserva el vástago, atraviesa la pieza a la altura de las rodillas ${ }^{14}$.

$\mathrm{Si}$ del punto de vista estilístico la figura encaja en los cánones de la koiné jónica, de la segunda mitad del siglo vi a.C., la iconografía corresponde a la de las mujeres que participan en el simposion. Estas representaciones están ampliamente documentadas durante este período y particularmente en la pequeña toréutica griega y magno-griega. Los paralelos más próximos corresponden a personajes tumbados, masculinos y femeninos, que originalmente decoraban vasos, calderos y otros objetos de bronce de grandes dimensiones, asimilables a un contexto de simposio $^{15}$. También en Etruria son habituales pequeñas figuras en bronce que muestran personajes tumbados en posición de relajación, que estarían aplicadas sobre vasos metálicos u otras series de objetos metálicos, indeterminados ${ }^{16}$.

Ante lo expuesto y en especial atención a criterios técnicos, la figura del Raso, debe excluirse como parte de un trípode $a$ verghette de producción vulcente pues los apliques de estos elementos toréuticos etruscos estarían fijados mediante soldadura o fundidos conjuntamente al anillo (Vid. Trípode de Karlsruhe)

\footnotetext{
${ }^{14}$ Es interesante destacar como una modalidad de fijación análoga se documenta en un aplique de personaje femenino recostado, fechado entre el siglo. V-IV a.C., en la colección etrusca del museo de Hannover (Gercke 1996: 198, N. 253).

${ }^{15}$ El catálogo más completo, con bibliografía precedente, en Bieg 2002: 130-141, 174-178. Tres figuras de banquetantes decoran también el trípode de la tumba XIII de Trebenishte (Stibbe 2003: 70, N. 3; 81, Fig. 43).

${ }^{16}$ Esta iconografía tuvo continuidad dentro de la pequeña toréutica, al menos, hasta el helenismo, como demuestra el incensiere de tipo Curunas del British Museum, con una decoración de cuatro figuras masculinas (Ambrosini 2002: 389, N. 407).
} 


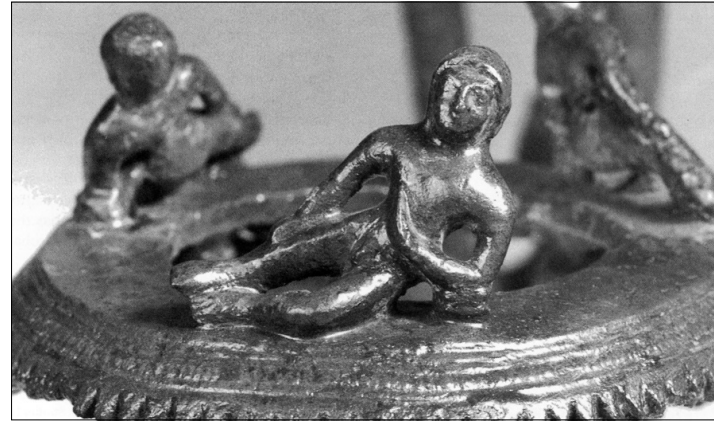

Figura 8. Detalle de la decoración figurada del anillo inferior del trípode $a$ verghette del Museo de Karlsruhe (Riis 1998: 61, Fig. 56.c).

y no por remaches ${ }^{17}$ (Fig. 8) manteniendo la interpretación como aplique de vaso.

\section{UN BAILARÍN DE RAFAL DEL TORO}

Conocido únicamente a partir de unos dibujos debemos considerar un bronce procedente del Predio de Rafal del Toro (Menorca) (García y Bellido 1948). A pesar que estos dibujos no sean de óptima calidad, es posible caracterizar la pieza (Fig. 9 y fig. 10). La figura representa a un personaje masculino en posición de Knielauf hacia la izquierda y muestra tanto el torso como la faz de frente, orientada hacia el espectador. Los brazos aparecen en jarra, extraordinariamente largos, con los codos hacia el exterior y las manos apoyadas sobre los costados de la caja torácica. A pesar que muchos detalles, particularmente de la cara, son quizás debidos al gusto del dibujante, la definición de los músculos abdominales y el peinado parecen fidedignos y asociados a la postura de la figura, datos que permiten encuadrarla en un horizonte del tardo-arcaísmo.

Por complicado que pueda parecer encontrar un paralelo a partir del dibujo, la figura en gesto de carrera encuentra similitud en un bronce griego de la colección de la Walters Art Gallery de Baltimo$\mathrm{re}^{18}$ (Fig. 11), fechable entre el 550 y el 530 a.C. (Riis 1938: 159); en el ejemplar sin contexto (N. inv. 17.759) del MAN-Atenas, fechado en la segunda

${ }^{17}$ Algunos casos presentan, en los anillos inferiores, perforaciones (Vid. Trípode del British Museum - N. Inv. 587, donde la perforación parece moderna). Las figuras aplicadas sobre los anillos inferiores de los trípodes no presentan, en ningún caso, perforaciones o fijación mediante remaches. Observación también realizada para los trípodes griegos (Bieg 2002: 130).

${ }^{18}$ Ex colecciones Sambon y Guilhou (Hill 1949: 69, n. 145, Tav. 31).

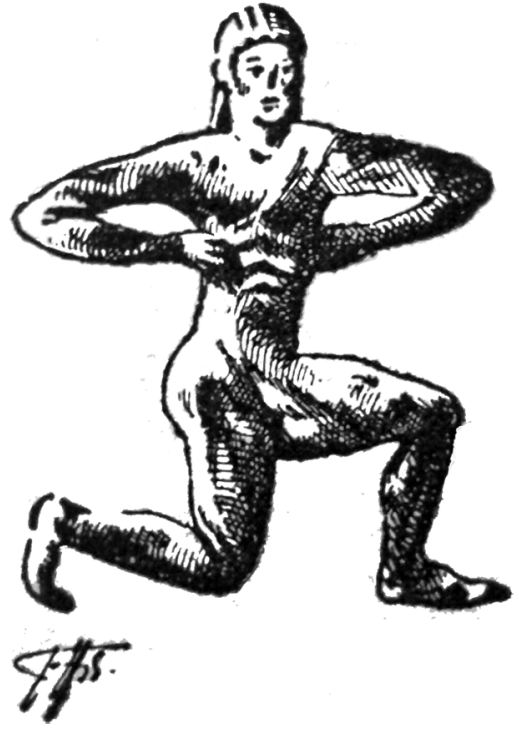

Figura 9. Dibujo 1 del bailarín de Rafal de Toro (García y Bellido 1948: 95, Fig. 30).

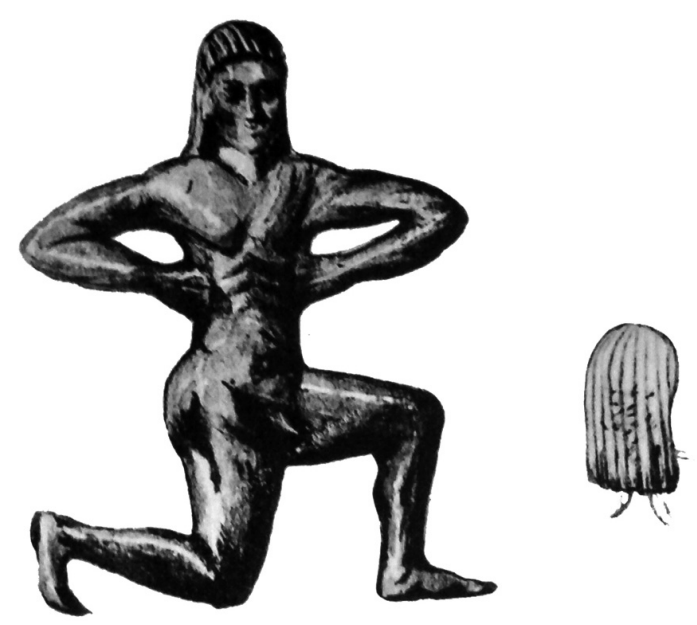

12. RAFAL DE TORO (MENORCA)

Figura 10. Dibujo 2 del bailarín de Rafal de Toro, con detalle posterior del peinado (García y Bellido 1948: Tab. XX, Fig. 12).

mitad del s. vi a.C.; y con ligeras variaciones, en otros tres pequeños bronces que decoran el borde de un dinós campano conservado en el Museo de Mariemont (fechado entre el último cuarto del siglo vi a.C. y el primer cuarto del v a.C. ${ }^{19}$ (Fig. 12); un aplique

${ }^{19}$ Benassai 1995, 167, N. D. 3 (con bibliografía precedente). Vale la pena añadir también las figuras que originalmente decorarían un lebes campano (de Cumas) hoy en el British Museum (Walters 1899: 28, N. 257). 


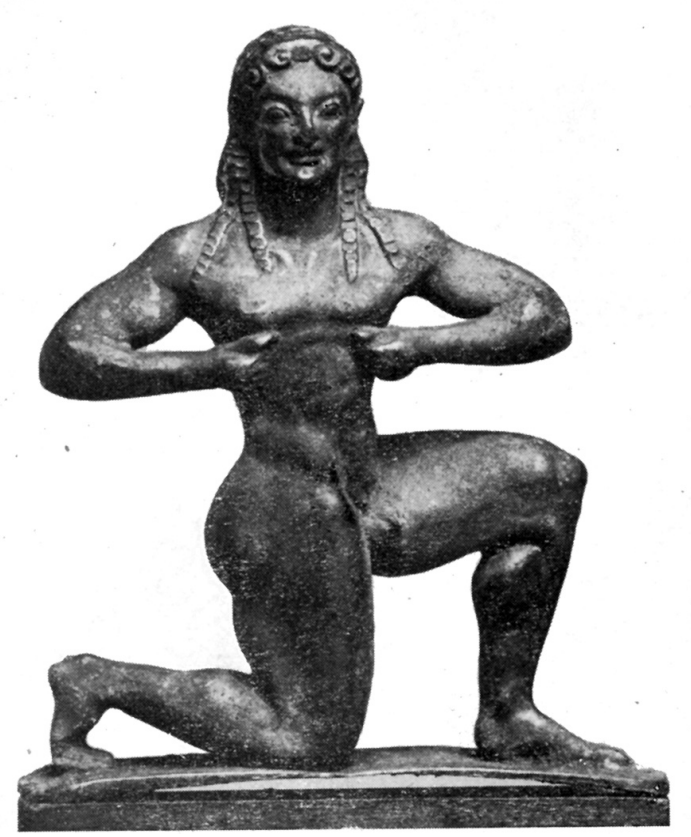

Figura 11. Figura del bailarín de la Walters Art Gallery de Baltimore (Hill 1949: Tab. XXXI).

en forma de corredor semidesnudo con inscripción sobre la pierna derecha exhibido en el Frank H. McClung Museum de Knoxville (Tennessee) ${ }^{20}$; y otro aplique, esta vez en forma de sileno y orientado hacia el lado opuesto, en la antigua colección Brommer - hoy en la Antikensammlung de Berlín ${ }^{21}$.

Los paralelos de Baltimore (N. Inv. 54.768) y Atenas (N. inv. 17.759), responden a una idéntica iconografía tanto por la estructura anatómica ${ }^{22}$ como por la posición del cuerpo y, especialmente, de los brazos, dispuestos en jarra. Las únicas diferencias corresponden al detalle del peinado, donde en los ejemplares de Baltimore y Atenas se observan las trenzas. Por otro lado, los tres jóvenes del dinós de Mariemont, aparecen también en una posición similar pero a diferencia de la pieza balear (y de Baltimore), los

\footnotetext{
${ }^{20}$ Exposición temporal: History Contained: Ancient Greek Bronze and Ceramic Vessels From the collections of Shelby White and Leon Levy Judy and Michael Steinhardt, Septiembre 17, 2005 - Enero 2, 2006.

${ }^{21}$ Cat. Brommer, Kat. Nr. 81, 27-28.

${ }^{22}$ El detalle anatómico pectoral, en este ejemplar, aparece claramente representado y con un trabajo cuidado, mayor del que presentan los dibujos de la pieza Balear. Lo mismo puede plantearse para el detalle del peinado y de la musculatura de las piernas, pero, como ya hemos comentado, los dibujos del ejemplar de Rafal de Toro - aunque realistas y concretos- pueden responder a un boceto o un dibujo que mostrara únicamente las características generales y no el detalle particular de toda la pieza.
}

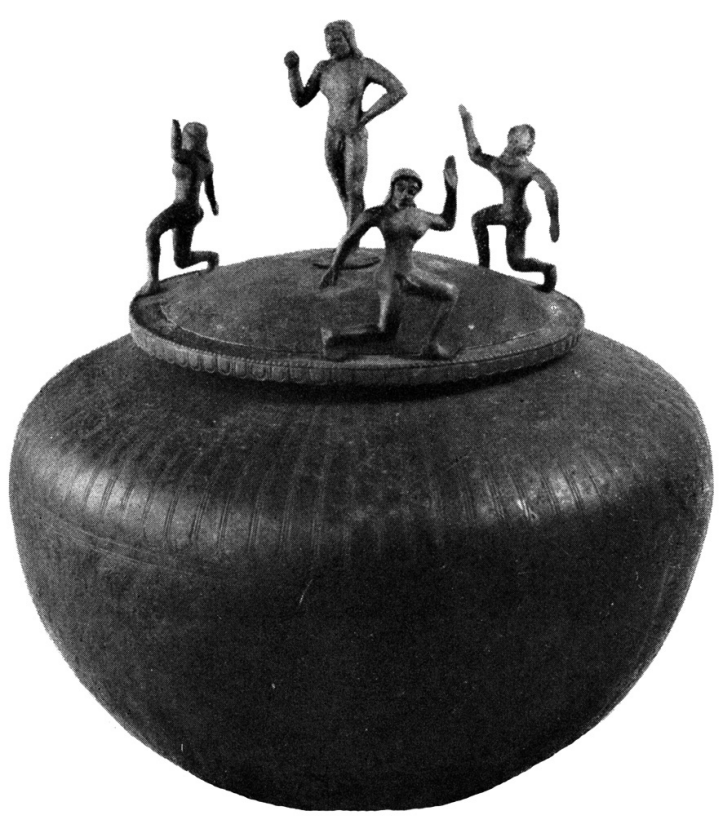

Figura 12. Dinos campano con decoración de jóvenes en posición de Knielauf y figura central del Museo de Mariemont (Les antiquités ... du Musée de Mariemont 1952: Tab. 46).

brazos están abiertos y flexionados, quizás representado el movimiento de la carrera u otro simbolismo. La estructura anatómica y el peinado de kourós constituye también aspectos de consonancia con el fragmento balear.

Los paralelos propuestos dirigen su interpretación hacia un gesto de danza ${ }^{23}$. Esto implicaría leer la figura de Rafal del Toro como la figura de un bailarín o, siguiendo las expresiones propuestas para los silenos peninsulares, un "kourós danzante". Esta propuesta corrige las apelaciones de komastés — tal y como podría llamarse si tomáramos como referencia una figura de Corfú (Dontas 1969) - o dromeús - tal y como lo han llamado García y Bellido (1948), Riis (1959: 47) y Olmos (1977: 378)—, pues la primera acepción dirigiría el significado hacia un ambiente simposíaco, para el que no tenemos suficientes evidencias, y el segundo adjetivo reduce la interpretación a la actitud de correr del personaje, que, como hemos visto, es más compleja.

Para este elemento, según la filiación de sus paralelos, se debe considerar de nuevo un contexto complejo. Por un lado Capua o el entorno etrusco-cam-

${ }^{23}$ Por lo que respecta a la posición de los brazos es posible recordar, además de los paralelos ya indicados (Baltimore, Knoxville Museum y Brommer coll.), una figura femenina interpretada como aplique y conservada en el RGZM de Mainz (Naso 2003: 25-27, N. 20). 


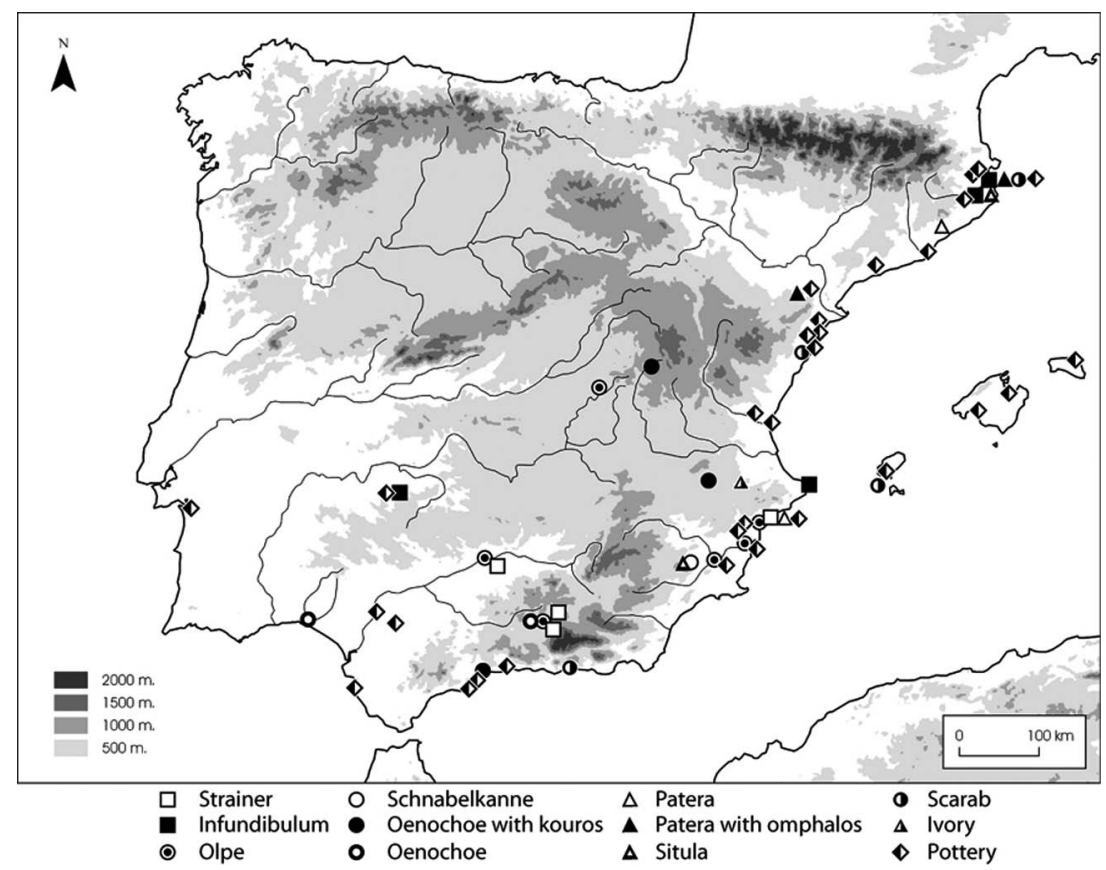

Figura 13. Mapa de distribución de las importaciones etruscas en la península ibérica. Dibujo: R. Graells.

pano, pero al mismo tiempo la transversalidad de su iconografía hace posibles otros contextos (Laconia o Etruria). En cualquier caso, el estilo de la pieza balear hace que consideremos los paralelos campanos como indicadores del origen más plausible. Recordemos que, aunque con datos de adquisición y de mercado anticuario, tanto los ejemplares de Baltimore como Mariemont procederían, también, de Capua ${ }^{24}$.

\section{SOBRE LOS ELEMENTOS DE VAJILLA METÁLICA ARCAICA EN LA PENÍNSULA IBÉRICA: CATÁLOGO}

La singularidad de estas representaciones figuradas debe entenderse después de su comparación con la realidad de las importaciones de vajilla metálica en la Península Ibérica y las Baleares. Si bien es ampliamente conocida la pluralidad de culturas y las diferencias entre los distintos territorios que ocupan esta

\footnotetext{
${ }^{24}$ A pesar que el ejemplar de Baltimore es de estilo griego. En cualquier caso podemos recordar que el dinámico mercado anticuario campano comerciaba habitualmente con piezas recuperadas en la mayoría de contextos de la Italia Meridional, con una especial atención a los hallazgos de las regiones de la Apulia o Basilicata. A este propósito debemos ser prudentes ante las aribuciones a Capua que no estén contextualizadas.
}

vasta área durante el arcaísmo y tardo-arcaísmo, creemos ilustrativo recopilar los vasos metálicos importados. Esta categoría corresponde principalmente objetos funcionales, de serie, y en ella son sospechosos los fragmentos de grandes vasos ${ }^{25}$. Esto no implica que la presencia de vasos extraordinarios no responda a unas élites locales que se apropiaron de esos elementos como transmisores de un estilo de vida y de un acceso privilegiado a unos recursos limitados, quizás también importados, pero particularmente los apliques figurados presentan demasiadas anomalías con el resto de importaciones de vajilla metálica (Fig. 13). El catálogo de elementos metálicos se relaciona siempre con el consumo de bebidas. Así, coladores e infundibula se mezclan con jarras (olpai, Schnabelkanne y enócoes), siendo sumamente extraña la presencia de otros elementos como ralladores, páteras (Graells 2011), simpula ${ }^{26}$ o los mencionados grandes

\footnotetext{
${ }^{25}$ Podemos recordar cómo, al menos, se documenta un aplique de crátera en Menorca y posiblemente puedan añadirse dos prótomos de caldero, uno de grifo y otro de toro (Graells 2006-2007), a los que ahora puede añadirse un fragmento de asa de crátera de grandes dimensiones recuperado en Empúries (éste sin discusión acerca de su segura procedencia), N. Inv. MAC-Empuries 8586.

${ }^{26}$ El único simpulum de cronología afín a la aquí considerada es el kyathos recuperado en el Pecio de la Cala Sant Vicenç, aunque no puede ser considerado como elemento importado (Graells 2007 y 2008a). Además, el estudio del
} 
vasos como cráteras, para las que deberá desarrollarse un discurso ad hoc. Quizás el dato más significativo sobre esta diferencia es que aparentemente la presencia de vajilla metálica etrusca corresponde a la primera serie (infundibula, olpai, coladores, etc.), mientras que la segunda serie, menor numéricamente, corresponde a importaciones campanas y/o magno-griegas (cráteras y páteras).

Si consideramos el catálogo, los coladores están representados por cuatro ejemplares concentrados en el sureste peninsular: en la tumba 32 de la necrópolis de Poble Nou (Vilajoyosa, Alicante) (Marcos Ruiz 2005: 77, Fig. 3; Botto y Vives-Ferrandiz 2006: 144), Alcurrucén- Pedro Abad (Córdoba) (Marzoli 1991; Pozo 2003), el Mirador de Rolando (Granada) (Pozo 2003) e Iznalloz (Granada) (Pozo 2003).

Los infundibula, en cambio, presentan una concentración dividida en dos áreas: que ocupa un foco en el entorno emporitano y otro desde el sureste hasta el interior. Actualmente se conocen hasta cinco ejemplares, fechados durante la segunda mitad del siglo VI a.C. y de producción de Volsinii (Orvieto) y/o Vulci:

1. Infundibulum de Ullastret (Baix Empordà, Girona): recuperado en el Estrato VI del Departamento 1 , excavado entre 1965 y 1966 y asociado a gran número de cerámica gris masaliota (Oliva 1976: 759, Fig. 23), fechable en la segunda mitad del siglo VI a.C. Se conserva únicamente la parte inferior (embudo) y corresponde al Grupo 1 de A. Naso (2006a y 2006b) (Fig. 14).

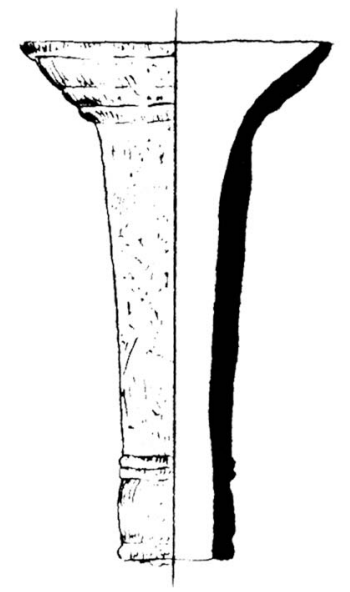

Figura 14. Embudo correspondiente a un infundibulum recuperado en Infundibulum Ullastret Estrat VI (Oliva 1976: Fig. 23).

material metálico de Empúries puede aportar cambios en este punto, si bien es cierto que se trata de un caso particular que no puede considerase como el resto de la Península.
2. Infundibulum de Empúries (Alt Empordà, Girona): recuperado en Sant Martí d'Empúries (campaña de 1998), corresponde a una figura de rana, pieza que se localiza actuando como bisagra para el colador del infundibulum. La pieza encuentra paralelos dentro del grupo 1 de A. Naso, particularmente en un ejemplar de Bisenzio tumba 74 (Naso 2006a: 381, N. 4; 2006b: 195, N. 4), de Belmonte Piceno tumba 163 o del Duce (Naso 2006a: 383, N. 18; 2006b: 195, N. 17), de Cyrene (Naso 2006b: 196, Fig. 9, N. 53) y en un ejemplar de procedencia desconocida del MANFirenze (N. Inv. 1538) (Naso 2006: 386, N. 30; 2006b: 195, N. 28), del MAN-Torino (N. Inv. 933) (Naso 2006a: 386, N. 34; 2006b: 195, N. 32) y del MANPerugia (N. Inv. 600) (Naso 2006: 386, N. 36; 2006b: 195, N. 33) (Fig. 15).

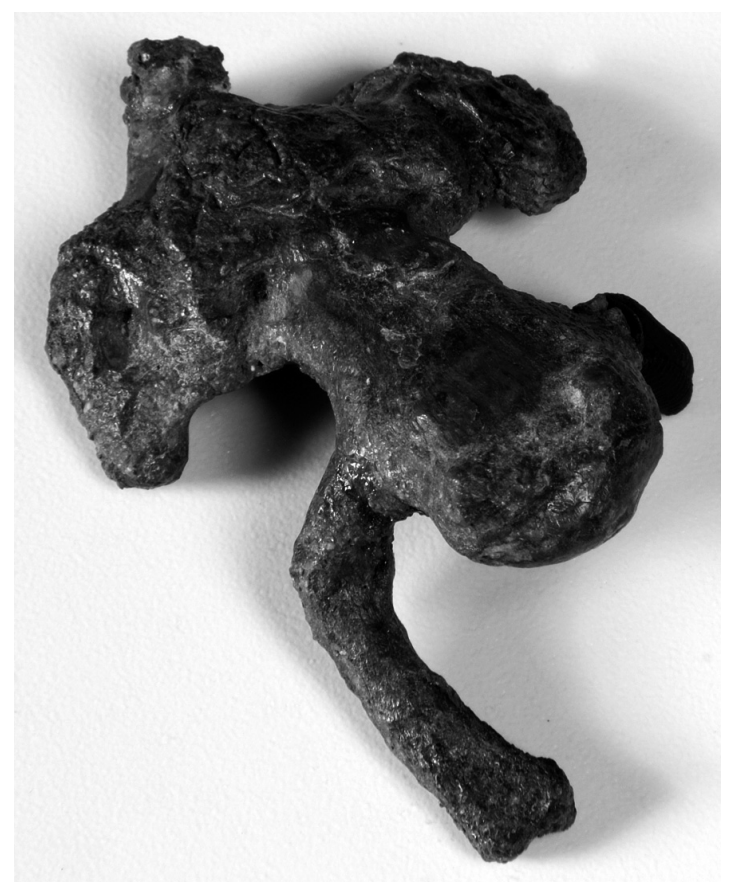

Figura 15. Fragmento de decoración de la bisagra de un infundibulum etrusco recuperado en Sant Martí d'Empúries (Foto: MAC-Empúries). Catálogo: animals d'Empuries. La fauna $i$ l'home a l'antiguitat, Girona 2007.

3. Infundibulum de Xàbia (Marina Baixa, Alacant), procede de una recuperación submarina (VivesFerrándiz 2007; Botto y Vives-Ferrándiz 2006, Fig. 55 y 56; Naso 2006a: 389, N. 57; 2006b: 196, N. 55). Corresponde al tipo 1 de A. Naso. A pesar de haber sido propuesta una cronología de primera mitad del siglo vi a.C., los paralelos obligan a rebajar la cronología y situarla en la segunda mitad de dicha centuria. Los paralelos corresponden a la variante más 
difusa dentro del tipo 1, pues presenta el remate del asa en forma de prótomo de ánade y una lira sencilla. El catálogo es: un ejemplar de la tumba dei Flabelli di Bronzo de Populonia (Livorno), de Populonia proceden dos ejemplares más, un ejemplar de Castelgiorgio (Terni), un ejemplar de la tumba 34 de Falerii Veteres (Viterbo), un ejemplar de la Tumba de la Biga de Castro (Viterbo), dos ejemplares de Todi (Perugia), un ejemplar de Cumas (Campania), y varios ejemplares sin procedencia conocida (Naso 2006a: 380-388, Nrs. 1-3, 6, 8-9, 11-12, 25, 32, 36, 42, 45-46, 51 y 54; 2006b: 195-196, Nrs. 1-3, 6, 8, $9,11-12,23,27,30,34,39,43-44,49$ у 52$)$.

4. Infundibulum de Cancho Roano (Badajoz): un ejemplar falto de la cazoleta y del colador con remate en prótomo de ariete (Botto y Vives-Ferrándiz 2006: Fig. 23; Celestino 1991: 78, Fig. 12a; Celestino y Zulueta 2003; Gran-Aymerich 2006: Fig. 3; Naso 2006a: 389, N. 56; 2006b: 196, N. 54). Corresponde al tipo 1 de A. Naso. El remate en forma de prótomo de ariete permite definir un subgrupo con pocos ejemplares: un ejemplar perdido de Ceregnano Adria (Rovigo) (Naso 2006a: 383, N. 15; 2006b: 195, N. 14), de Casal fiumanese (Bologna) (Naso 2006a: 383, N. 17; 2006b: 195, N. 16), sin contexto en el Metropolitan Museum NY (N. Inv. 34.11.8) (Naso 2006a: 287, N. 40; 2006b: 196, N. 38) y en el Manchester Museum (N. Inv. 29973) que podría corresponder al ejemplar de Ceregnano (Naso 2006a: 387, N. 45; 2006b, 196: N. 43).

5. Infundibulum de Cancho Roano (Badajoz): ejemplar fracturado del que se conserva la unión, en forma de palmeta, del mango con la cazoleta y el colador (Botto y Vives-Ferrándiz 2006: Fig. 23; Celestino 1991: 78, Fig. 12b; Celestino y Zulueta 2003; Gran-Aymerich 2006: Fig. 3; Naso 2006a: 392, N. 68; 2006b: 196, N. 66). Corresponde al tipo 3 de A. Naso. El grupo lo integran únicamente 3 ejemplares que además del de Cancho Roano son: un ejemplar considerado procedente de Nola en el Musée Royal de Brussels (N. Inv. R.1127) (Naso 2006a: 392, N. 66; 2006b: 196: 64) y otro de procedencia desconocida en el Kunsthistorisches Museum de Viena (N. Inv. VI932) (Naso 2006a: 392, N. 67; 2006b: 196, N. 65).

En cuanto a páteras, el catálogo debe considerar únicamente dos tipos. Por un lado las páteras de tipo Cook, documentadas en la tumba de les Ferreres de Calaceite y en el entorno emporitano (Graells 2010: 87-89; Graells y Armada 2011) y la serie griega, integrada por el fragmento de asa de pátera de la tum- ba de la Diosa de Galera y el asa de la Covalta. Las supuestas importaciones de páteras de borde perlado o plano etruscas no pueden considerarse ante la falta de correspondencia con los tipos originales. Como se observa, la distribución de los tipos define dos focos de interés, quizás casual ante la escasez de casos, que deberá compararse con el resto vasos metálicos importados: la serie etrusca situada al noreste de la Península Ibérica y la serie griega al sureste.

Además, podemos añadir dos apliques de asa de sítula etrusca de Ullastret (N. Inv. 2981 y 3688), procedentes de los niveles removidos al este de la torre medieval y sin contexto que han sido fechados entre finales del siglo vi a.C. e inicios del v a.C. (Sanahuja 1971; Graells 2006: 202-203; 2007, 113, nota 55) (Fig. 16).

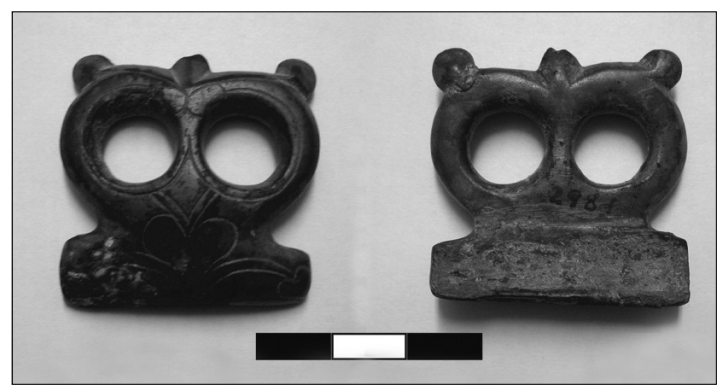

Figura 16. Aplique de asa de sítula etrusca de Ullastret (MAC-Ullastret N. Inv. 2981) (Foto: R.G.).

Los olpai con asa sobreelevada, para los que la cronología propuesta hasta ahora parece demasiado amplia (siglos v-II a.C.) y debería concretarse en el siglo v a.C., están representados por ocho ejemplares, siete de ellos localizados en el área sureste de la península Ibérica y otro más en el área interna del levante peninsular. El catálogo lo integran las piezas de El Oral (Alacant) (García Cano 1991), Alcurrucén-Pedro Abad (Córdoba) (Marzoli 1991: Lám. I y II), Escuera (Alicante) (Llobregat 1982), Mirador de Rolando (Arribas 1967), 2 ejemplares de la antigua colección Saavedra (hoy en el MAN y de posible procedencia andaluza) (Blázquez 1960), Necrópolis del Cabecico del Tesoro T.255 (García Cano 1991) y necrópolis de Haza del Arca (Lorrio y Sánchez 2002: 164 169-170 y 186$)^{27}$. También en esta área particularmente rica en cuanto a vasos importados, se documentó el único Schnabelkanne recuperado en la Península Ibérica, en la Necrópolis del Cigarralejo, tumba 57.

Más complejo es el caso de los enócoes con asas en forma de kouroi que representan la categoría de

\footnotetext{
${ }^{27}$ Pieza tradicionalmente llamada "olpe de Segóbriga".
} 
vasos metálicos más elaborada en cuanto a implicaciones iconográficas. Este grupo concentra sus tres hallazgos en la zona interior del levante peninsular:

1. El asa de Cuenca (Graells 2008b), se presenta fracturada, conservándose únicamente la parte central del cuerpo del kourós, desde el pecho hasta la parte baja de la pierna. La curvatura y estructura del cuerpo coincide con la del kourós del jarro de Schwarzenbach, así como sus dimensiones. Todos los paralelos permiten considerar el fragmento como una producción etrusca, de un taller de Vulci o de la Etruria septentrional. La cronología es la misma que para el jarro de Schwarzenbach circa 500 a.C. (Hill 1958: 200). A pesar de la filiación de la pieza, el grado de fragmentación impide asegurar con rotundidad a qué tipo de pieza correspondió. A nuestro modo de ver las dimensiones, la curvatura y los paralelos más próximos llevan hacia un asa de jarro del tipo $S c h$ nabelkanne.

2. El asa de Málaga fue hallada en la ladera de la Alcazaba de Málaga a inicios del siglo xx. Su estructura puede considerarse una de las más complejas y ricas de cuantas se conocen. Los Aqueloos y la compleja escena del remate inferior encuentran abundantes paralelos dentro de la toréutica etrusca, destacando especialmente los remates inferiores de asas con escenas complejas. Según Adam (1984: 5), sobre la base de Brown (Etruscan Lion Group IIIA, 123124), corresponde a una producción de Vulci del primer cuarto del siglo $\mathrm{v}$ a.C. La cronología que propone Blanco (1965), en cambio, es de 480-470 a.C., mientras que M. Botto y J. Vives (2006) la fecharon entre el 530 y el 475 a.C. ${ }^{28}$.

3. El asa de Pozo-Moro, se recuperó debajo del monumento turriforme de la necrópolis de Pozo Moro en una pira junto a distintos materiales como un kylix ático del pintor del Pithos y un lekythos de la clase Atenas 581 además de varios objetos en oro y plata. Corresponde a la parte superior de una figura de kourós con los brazos flexionados. Th. Weber (1983) la incluyó en su serie etrusca de producción vulcente. Se fecha en torno al 500 a.C., coincidiendo el kylix, el lekythos y el asa (Almagro-Gorbea 1983: 188; 2009: 77).

En el Mediterráneo occidental, las representaciones de vasos con kouroi presentan un testimonio dis-

${ }^{28}$ Recientemente H. Hiller ha propuesto que se trate de un producto griego oriental (Comunicación personal). tinto, conocido únicamente gracias a un dibujo antiguo. Entre los hallazgos antiguos de las islas Baleares, destaca un mango antropomorfo procedente de Mallorca (Graells 2011). Este hallazgo aconteció hacia 1835, dándose a conocer poco después con breve descripción y reproducción en el Voyage en Sardaigne (Paris, 1840) de A. della Marmora ${ }^{29}$. La pieza corresponde a un mango de pátera de tipo arcaico con una cabeza de carnero en la parte inferior. Sobre esa se coloca un joven kouros desnudo con los brazos en ángulo recto soportando una escena con dos carneros contrapuestos. Los animales aparecen enmarcados por un pedestal acabado, en ambos lados, por dos volutas y encima de sus lomos por otro pedestal, de menores dimensiones, que tiene como particularidad la colocación de las volutas en la parte interior de la escena, justo en la nuca de los carneros. Entre los dos carneros aparece una palmeta. Este tipo de pátera puede considerarse dentro del tipo II A de Gjødesen, con paralelos en el ejemplar de la t. 126-1977 de la necrópolis del Purgatorio de Rutigliano (Tarditi 1996: 108-109, Cat. 247), de la 218 de località San Vito en Guardia Perticara (Bianco 2002: 220) y de otro ejemplar de Olimpia (Gjødesen 1944: N. 57; Tarditi 1996: 175). Estos ejemplares identifican un pequeño subgrupo, posiblemente de un mismo taller (Tarditi 1996: 175). Si bien la heterogeneidad del grupo II A de Gjødesen permitiría pensar en una pluralidad de talleres, que para M. Gjødesen serían exclusivamente de ámbito magno-griego (Gjødesen 1944: 140) y para Ch. Tarditi entre la Magna Grecia y el Peloponeso (Tarditi 1996: 175).

Si se considera esta pequeña producción como procedente del Peloponeso, este ejemplar viene a constituir prácticamente el único vaso metálico griego que llega al extremo occidente mediterráneo durante el arcaísmo. En cambio, si consideramos la producción magno-griega, encontramos mejor encaje gracias a los dos casos en territorio italiano y al comportamiento mayoritario de las importaciones de vajilla metálica hacia occidente. De esta manera el ejemplar español se sumaría a la pequeña lista de vasos metálicos de esa procedencia: un kyathos de producción campana (Graells 2007 y 2008a), el discutido aplique de asas de la Covalta $^{30}$ (Fig. 17) y el

\footnotetext{
${ }^{29}$ Citado en García y Bellido 1945: 285, con la figura reproducida en la Fig.2. en el artículo de García y Bellido aparece también otra reproducción realizada por $\mathrm{G}$. Llompart (García y Bellido 1945: 286, Fig.3).

${ }^{30}$ García y Bellido 1941: 531-532, Fig. 23; Graells 2007: Fig.13; Vives-Ferrándiz 2006-2007. Decorado con una palmeta, que presenta paralelos en una lekanis de bronce procedente de Votonosi (Metsovo, Grecia) (Vocotopoulou 1975: 733), en el psykter de bronce del Metropolitan Museum de
} 


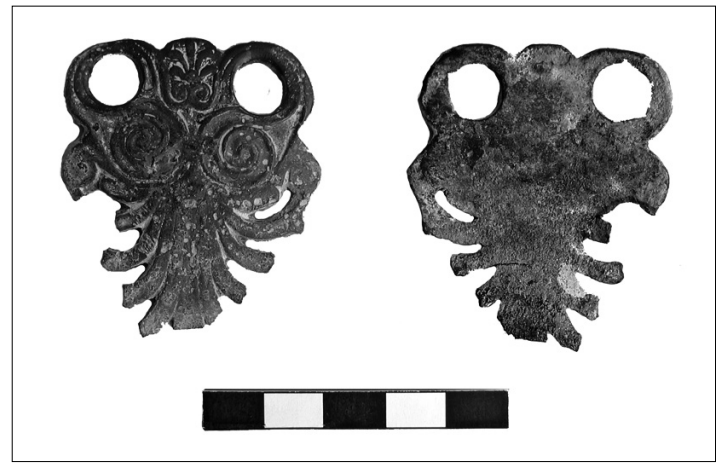

Figura 17. Aplique de asa de la Covalta (Vives-Ferrándiz 2006-2007: 320, Fig. 6)

aplique de crátera de Menorca (Arribas et alii 1987; Graells 2006-2007; Graells 2007).

Siguiendo en las Islas Baleares, recordemos un mínimo de tres cráteras de bronce de distintos contextos y cronologías. Un aplique en forma de figura de toro caminado hacia la izquierda, que se encuentra en el Museu Diocesà de Ciutadella (Menorca) (Kukahn 1969; Belén y Fernández-Miranda, 1979: 156; Graells 2006-2007: 299, Fig. 4) y dos fragmentos de cráteras de volutas de tipo suritálico hallados en el pecio del Sec (Mallorca).

\section{SOBRE LOS ELEMENTOS DE VAJILLA METÁLICA ARCAICA EN LA PENÍNSULA IBÉRICA: DISCUSIÓN}

El significado de la vajilla metálica parece indicar una marcada ostentación de riqueza que distingue a personas o pequeños grupos económica y socialmente elevados. En la Península Ibérica, este hecho se combina con la rara destinación de estos objetos como elementos de carácter religioso. En cambio, se amortizan mayoritariamente al ámbito funerario. Así, la exhibición de la iconografía y del acceso al simposion se convierte en manifestaciones del poder. De esta manera, puede aceptarse una "aculturación" de las élites locales mediante productos de alto valor, que esas élites tendrían reservados. En cualquier caso, no puede considerarse que las relaciones entre los objetos producidos y consumidos y los fenómenos de acultu-

NY (Von Bothmer 1961: 141, Fig.7-8.) y en distintos apliques de sítulas campanas. El ejemplar valenciano, propuesto como procedente de un taller tarentino (García y Bellido 1948: 109, Lám. XLIII, 25), ve confirmada su atribución en base a los paralelos, que se fechan de manera homogénea entre finales del siglo vi e inicios del siglo v a.C. (Stibbe 1997, Rolley 1982), aunque no podemos afirmar a qué tipo de recipiente corresponde. ración sean siempre directos ni unívocos. Los fenómenos de aculturación no responden exclusivamente a un intercambio o comercio de objetos de prestigio, sino el acceso a un comercio de semi-lujo, de mayor dimensión. Se opone así la idea entre el objeto singular, que se fabricaría por encargo, con el objeto de serie, habitual para el comercio regular y frecuente en sociedades o consumidores nuevos y en formación (Gran-Aymerich 1986: 44), quizás a través de una progresiva impregnación mediante la iconografía que decoraba esos mismos vasos. La introducción de una nueva forma de celebrar el banquete (con implicaciones tanto ideológicas como materiales) fue fundamental para la transmisión de un estilo de vida aristocrático común en el Mediterráneo arcaico, aunque dimensionado a cada territorio. El elemento que puso en relación estas nuevas actitudes no fue solo el vino, sino que puede aceptarse como la vajilla metálica, como símbolo de prestigio más allá de su valor intrínseco, dominaría la escena y concentraría la nueva ceremonia simposíaca destacando el estatus de los personajes emergentes.

En este cuadro, la presencia de vajilla metálica arcaica, aunque escasa, es sumamente indicativa tanto tipológicamente como a nivel de distribución espacial. Así, resulta necesaria la observación conjunta de la totalidad de la Península Ibérica. Repetidamente se ha planteado la rareza de la circulación de los vasos metálicos, que contrasta con los elementos para servir y condimentar las bebidas. De manera que siguen siendo útiles las palabras de B. Bouloumié que consideran poco corrientes, aunque revestidos de prestigio, los vasos metálicos etruscos y griegos en contextos "bárbaros" (Bouloumié 1985: 169; 1986: 72). Esto podría entenderse en un marco en el que el vaso metálico fuera fácilmente reconocido como elemento de valor y estatus lejos de su origen, bien los vasos de grandes dimensiones como los técnicamente complejos, que despertarían la curiosidad, como los infundibula. El problema en el Mediterráneo occidental es la identificación de repeticiones y mapas de distribución por tipos de manera que tienen que combinarse y presentar panorámicas que combinen tipos distintos bajo un marco cronológico unitario.

A nadie sorprende hoy la presencia en contextos "bárbaros" peninsulares de elementos de vajilla metálica producidos en contextos etruscos y griegos (véase también magno-griegos). Este hecho puede identificar algunas de estas producciones con elementos destinados a abastecer un mercado, en base a una demanda o para satisfacer un encargo. Si comentábamos la singularidad de algunos recipientes metálicos hallados en la Península Ibérica (caso del gri- 
fo de Sevilla o las asas de crátera del pecio del $\mathrm{Sec}^{31}$ ), el caso del enócoe de Pozo Moro o los infundibula de Cancho Roano muestran la singularidad de los personajes y contextos a los que fueron destinados o que podían acceder a este tipo de importaciones y, al mismo tiempo, la comprensión, uso y asociación al estilo mediterráneo. En cambio, otros elementos menores, como los kyathoi, son ausentes en contextos indígenas continentales y permiten considerar su uso como limitado, en relación a unas costumbres no exportadas, ligadas a la idiosincrasia del lugar de producción (un ejemplo en Graells 2007).

La Península Ibérica presenta una particularidad respecto a lo que ocurre en el Sur de Francia. En la Península Ibérica se documentan numerosos elementos auxiliares del set de banquete metálico etrusco y algunos vasos de producción suritálica (etrusco-campana y magno-griega), que son ausentes en el Sur de Francia si excluimos el caso de Vix o Sainte-Colombe (y posiblemente también, de ser cierto, el hallazgo del grifo de Sainte-Gemmes-sur-Loire).

Si bien los materiales etruscos tienen una distribución que parece responder de manera distinta a las varias áreas de recepción a lo largo del litoral, los elementos de vajilla metálica suritálicos presentan una concentración en las Islas Baleares y Empúries, así como una serie de hallazgos dispersos inconexos. Particularmente la presencia de los tres elementos que han centrado la atención del presente artículo. Tres apliques de difícil filiación, dos de los cuales posiblemente parte de vasos etrusco-campanos y un tercero de difícil identificación. Tres fragmentos figurados, dos de ellos con contexto coherente y un tercero (en el Raso) sin contexto ni una propuesta de dinámica de contactos o recepción de importaciones que permita aceptar absolutamente su verdadero hallazgo. Tres figuras estilísticamente relacionadas entre sí, dos de las cuales con un estilo arcaico posiblemente etrusco-campano y una tercera de estilo etrusco clásico. En definitiva, tres piezas que escapan a la tipología normal de las importaciones arcaicas hacia el occidente mediterráneo.

Antes de terminar este apartado, creemos importante recordar las diferentes propuestas acerca de la distribución de vajilla metálica itálica hacia occidente. Por un lado, la circulación vehiculada a través de un sistema empórico, propuesta que ha gozado de cierta aceptación más por la comodidad que por los datos concretos que aporta. Una propuesta que interpreta

\footnotetext{
${ }^{31}$ Sobre el grifo vid. Graells 2006-2007: 296-298; Sobre las asas vid. Graells 2006-2007:299, nota 299; 2007: 110114, Fig. 12. F.
}

una circulación directa, sin intermediarios, difícil de aceptar ante la presencia aislada de piezas metálicas singulares descontextualizadas respecto a otros elementos, véase cerámica. Por otro lado, una alternativa ha sido ver una multiplicidad de sistemas, combinando casos de relación directa con otros de comercio empórico y añadiendo también intercambios locales, puntuales, e intercambio de dones y regalos. Ante esta amalgama de situaciones, las dinámicas generales, observables a partir de mapas de distribución pueden ayudar y paliar la falta de información. Particularmente complicado es el caso de la distribución de la vajilla metálica de tipo sur-itálico hacia la Península Ibérica, para el que se ha propuesto un intercambio directo (Graells 2007: 114; 2011).

\section{CONCLUSIONES}

Afirmaba M. Lutero que Wer nicht liebt Wein, Weib, Gesang, der bleibt ein Narr sein Leben lang. A tal efecto R. Strauss exaltó esos tres conceptos en 1869 en el vals que da título al presente trabajo, porqué si los apliques de seres mitológicos o híbridos habían llamado la atención de la investigación las figuras del banquetante ebrio, la muchacha etrusca y el bailarín han quedado relegadas a un segundo plano del discurso. Así, la aproximación tipológica de los tres fragmentos aquí considerados permite corregir afirmaciones de peso sobre los mismos, con implicaciones de mayor calado en el discurso sobre las importaciones tardo-arcaicas hacia la Península Ibérica.

Recapitulando: La figura del santuario de la Algaida fue interpretada desde sus primeras publicaciones como un aplique etrusco (Corzo 1991), posteriormente, aunque faltando paralelos para afirmarlo, se ha ido difundiendo la idea de su pertenencia a un trípode etrusco. A nivel contextual, entre el material asociado al fragmento, llama la atención la ausencia de otros fragmentos de trípode así como otros materiales de procedencia etrusco-arcaica. Únicamente dos pies de cista, para los que hemos presentado ciertas dudas acerca de su sincronía con la figura, podrían indicar un influjo etrusco, quizás periférico. A diferencia de lo expuesto tradicionalmente, el análisis detallado obliga a ser prudentes acerca de la "etrusquidad" del banquetante de la Algaida, a partir de paralelos que suponen contextos alternativos, como la problemática tapadera de lebes de tipo campano (posiblemente capuano), y los paralelos, tardíos, de uno de los pies de cista asociados en el santuario, que encuentran su filiación en las series prenes- 
tinas. Así, si consideramos el estilo y los paralelos del fragmento nos vemos obligados a proponerlo como una producción de carácter etrusco, de un taller menor. En cualquier caso, su morfología permite afirmar que no corresponde a ninguna pieza de trípode etrusco ante la ausencia de cualquier paralelo o pieza próxima.

La pieza del Raso, excepcional en el contexto de hallazgo por su desconexión tipológica e iconográfica con los materiales locales y la distancia con el ámbito mediterráneo, supone problemas de interpretación, partiendo, quizás, de la misma veracidad sobre su origen en la zona del Raso. Dejando de lado, ahora, este problema, de cariz historiográfico, y aceptando su recuperación abulense como genuina, los problemas de la pieza son de carácter funcional más que de filiación. La iconografía, claramente etrusca, no ofrece dudas. En cambio, la posición original de la pieza no está clara y no ayudan comentarios como los propuestos por M. Mariné que afirma que la pieza fue adquirida por un "aristócrata" local ya como pieza independiente — como indicaría la total ausencia de otros fragmentos relacionados con ella-. A tal efecto, los argumentos tecnológicos impiden interpretar esta figura como un ornamento de trípode etrusco y, a pesar de la parquedad de paralelos, debemos suponer que corresponda a una decoración de borde de vaso.

El fragmento procedente del Predio Rafal del Toro ha supuesto, desde el inicio, diversos problemas. El primero corresponde a la limitación objetiva para su análisis, pues disponemos únicamente de un dibujo de la pieza. El segundo, la posición del personaje no encaja en las series presentes, por ejemplo, sobre trípodes etruscos pues se muestra el detalle dorsal, hecho que permite suponer que en origen sería visto $\mathrm{y}$, por consiguiente, supone una fijación sobre el borde o tapadera de un vaso. Finalmente, la posición de los brazos, en jarra, y de las piernas, complica un debate acerca de su representación. El análisis permite dudar, también de la etrusquidad de la pieza a favor de una tradición, menor, periférica como hemos visto también en el anterior ejemplar de la Algaida. Aun así, los paralelos etrusco-campanos y el estudio de la posición del kourós permite ahora reconocer al personaje como un bailarín, muy posiblemente en posición de decoración de una tapadera de cista de lebes capuano.

$\mathrm{Si}$ intentamos contextualizar estos bronces figurados debemos añadir otros tres, conocidos como Centauro de Royos (García y Bellido 1948: 87-89; Riis 1959: 47; Olmos 1983 y 2000a; Croissant y Rouillard 1997: 55-66), (Fig. 18 A y B) Sátiro itifálico del Llano de la Consolación (García y Bellido

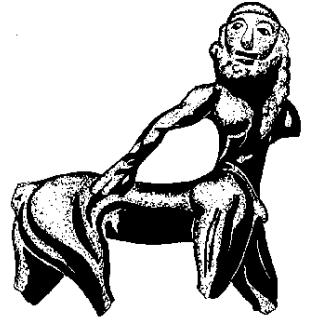

A

B

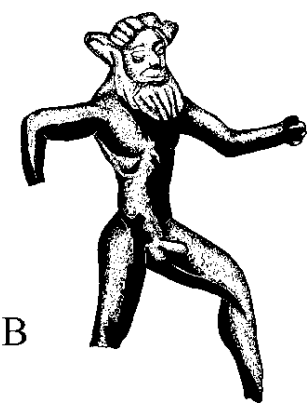

Figura 18. Dibujo de la figura del Centauro de Royos y el Sátiro del Llano de la Consolación (García Cano 1991: 382).

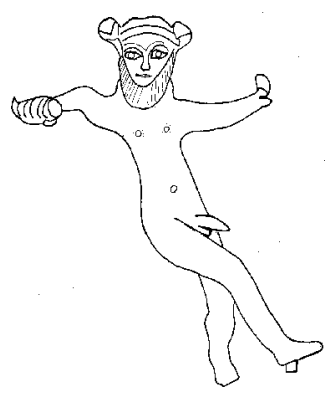

Figura 19. Dibujo de la figura del sileno de Capilla (Olmos 1977: 374, Fig. 2).

1948: 91-93; Herfort-Koch 1986: 121, K153; Olmos 2000b) y Sileno de Capilla (Almagro-Gorbea 1977: 251; Olmos 1977; Olmos y Sánchez 1995: 115; Croissant y Rouillard 1997; Prados 1997: 89; Rodero 2000) (Fig.19). El primero magno-griego, el segundo laconio y el tercero posiblemente de procedencia suritálica, no sin discusión al proponerse también un taller local para el sileno (Croissant y Rouillard 1997: 59; Rodero 2000: 89) $)^{32}$.

De esta manera, si la presencia de estos bronces figurados arcaicos y tardo-arcaicos en ámbito ibérico fue considerada por R. Olmos en una relación "fundamentalmente funeraria" (Olmos 1983: 385) y para otros a la actividad comercial (Prados 1997: 91), creemos que al menos dos de los casos que aquí hemos considerado responden a un uso e imaginario

${ }^{32}$ Sobre éste último ejemplar, R. Olmos no identificó paralelos concretos (Olmos 1977, 376-377) a pesar de proponer unas genéricas atribuciones como aplique para el borde de un vaso o dinos. Si atendemos brevemente las características estilísticas del sileno y su cronología (primer cuarto del siglo v a.C.), vemos como coinciden con los dos apliques que hemos analizado e interpretado como elementos de dinoi campanos, categoría de vasos en la que la representación de silenos y figuras danzantes es frecuente (Benassai 1995: Cat. I.4, I.8, I.12). 
distinto, centrado en la celebración convival del simposio. Quizás, como acertadamente señalaba R. Olmos cuando incidía en el aspecto del centauro como representación alejada de la imagen humana, debamos distinguir entre las representaciones de seres híbridos o mitológicos y las representaciones humanas y considerarlas como exponentes de ámbitos conceptualmente opuestos. Pero lejos de intentar aproximarnos a como los íberos comprendieron o utilizaron estos apliques, para lo que se han planteado hipótesis interesantes, volvamos a analizarlos e intentemos encajar los resultados de los bronces aquí estudiados con su contexto.

La distribución de los vasos metálicos arcaicos con figuras aplicadas (aquí los apliques como pars pro toto) en la Península Ibérica difiere fuertemente de la dispersión del resto de vasos metálicos arcaicos, pero otros dos elementos enlazados entre sí hacen aún más singular a este grupo. Todos los casos considerados en el trabajo, y los tres que hemos añadido en párrafos anteriores con la sola excepción del de la Algaida, son hallazgos casuales, descontextualizados e inconexos con los materiales recuperados en los supuestos puntos de procedencia. Además, son casos inconexos entre sí y que no encajan en la norma de los vasos importados en la Península que hemos recopilado anteriormente. Esto no invalida la posibilidad de que procedan de hallazgos peninsulares, pero es difícil encajarlos en los supuestos contextos donde se dice que fueron recuperados. Por un lado, el estado de conservación de todos ellos y, por el otro, el hecho de corresponder tipológicamente a producciones muy particulares debería hacer dudar seriamente de ello.

La presencia de bronces laconios y magno-griegos hacia contextos fenicios no encuentra ejemplos y en contextos celtas se concentran en ambientes particularmente dinámicos dentro del sistema de los Fürstensitze. Por otro lado, la circulación de dinoi campanos fuera de la Campania es un fenómeno prácticamente no documentado ${ }^{33}$. De esta manera, los apliques figurados de la Península y las Baleares, del que únicamente el de la Algaida tendría contexto y explicación en el marco de un santuario, definen un fenómeno de relaciones excepcionalmente ricas con el mundo etrusco-campano o suritálico que no encuentra correspondencia en los datos arqueológicos contextualizados y fiables. Únicamente dos excepcio-

${ }^{33}$ Únicamente un dinos relacionable con estas series fue recuperado en la necrópolis de Santa Caterina Vecchia (Perugia) el 1869, aunque las características morfológicas indican un taller distinto, mezclando elementos de producciones campanas y etrusco internas (Benassai 2002). nes pueden considerarse gracias al contexto: el pecio del Sec y el de la Cala Sant Vicenç. El primero, con fragmentos de cráteras, propone un modelo alternativo que debemos relacionar con las aristocracias Ibéricas del sur peninsular. El segundo caso, en cambio, muestra como algunos elementos de banquete, que en la Península distorsionarían el registro, corresponden al equipo de la tripulación. Por lo tanto son muchas las dudas para poder explicar tal concentración de casos y su verdadero significado ideológico y social.

En conclusión, la propuesta con la que la tradición investigadora ha identificado a algunos de los fragmentos aquí considerados como apliques de trípodes etruscos queda invalidada y se confirma como, hasta el momento, en la Península no se documentan fragmentos de trípode (ni etruscos ni griegos) ${ }^{34}$. Por otro lado, la filiación estilística de los fragmentos, ahora corregida, considera el estilo jónico como anómalo en series etruscas típicas que obliga a considerar el fragmento de la Algaida y el de Rafal del Toro como producciones periféricas, quizás de tipo etruscocampano. Finalmente, el dato importante es el de presentar argumentos para dudar sobre la procedencia de dos de las piezas aquí consideradas (extensible a otros apliques de seres híbridos) pues no encajan ni en la lógica de las importaciones etrusco-itálicas ni en los supuestos contextos de procedencia.

Los tres apliques que hemos analizado vienen a modificar el panorama acerca de las importaciones de bronces figurados tardo-arcaicos en occidente, anómalos más allá de las asas de enócoes vulcentes y del curioso catálogo de piezas extraordinarias sin contexto del sur peninsular y Extremadura que ahora debemos reducir a un único ejemplar, en el santuario de la Algaida.

\section{BIBLIOGRAFÍA}

Adam, A. M. 1984: Bronzes étrusques et italiques, Bibliothèque Nationale, Paris.

Almagro-Gorbea, M. 1977: El Bronce Final y el Período Orientalizante en Extremadura. Bibliotheca Prehistórica Hispana XIV, Madrid.

${ }^{34}$ Actualmente conocemos únicamente dos dinoi campanos fuera de su área original: en primer lugar, un dinos procedente de la necrópolis de Santa Caterina Vecchia (Perugia), hallado en 1869, aunque las características morfológicas indican un taller ligeramente distinto, mezclando elementos de producciones campanas y etrusco internas (Benassai 2002); en segundo lugar, una figura de un joven desnudo, interpretada como decoración de un dinos, que corresponde a un hallazgo sin contexto en Wallerstein-Ehrigen (Alemania) (Guggisberg 2005). 
Almagro-Gorbea, M. 1983: "Pozo Moro. El monumento orientalizante, su contexto socio-cultural y sus paralelos en la arquitectura funeraria ibérica", Madrider Mitteilungen 24, 173-293.

Almagro-Gorbea, M. 1992: "Gli Etruschi e la penisola Ibérica", M. Pallotino (ed.), Gli Etruschi e l'Europa, Milano-Paris, 174-179.

Almagro-Gorbea, M. 2009: "El Kylix de figuras rojas arcaicas de Pozo Moro (Albacete)", Quaderns de prehistòria i arqueología de Castelló 27, 6381.

Ambrosini, L. 2002: Thymiateria etruschi in bronzo di età tardo classica, alto e medio ellenistica, Roma.

Aquilué, X., Castanyer, P., Santos, M., Tremoleda, J. 2006: "El comercio etrusco en Emporion: evidencias sobre la presencia de materiales etruscos en la 'Palaia Polis' de Empúries", Gli etruschi Da Genova ad Ampurias. Atti del XXIV Convegno di Studi etruschi e italici, Pisa, 175-192.

Arribas, A. 1967: "La necrópolis bastitana del Mirador de Rolando (Granada)", Pyrenae 3, 67-105.

Arribas, A., Trias, G., Cerdá, D. y De Hoz, J. 1987: El Barco de El Sec (Costa de Calviá, Mallorca). Estudio de los materiales, Mallorca.

Asensi, R. M. 1991: "Los materiales etruscos del orientalizante reciente y período arcaico de la Península Ibérica: Las cerámicas etrusco-corintias de Ampurias", J. Remesal y O. Musso, (eds.), La presencia de material etrusco en la Península Ibérica, Barcelona, 225- 238.

Bardelli, G. e.p.: "Cavalli senza cavalieri. Il tripode di Cap d'Agde e i tripodi etruschi tardoarcaici con protomi equine", Contacts et acculturations en Méditerranée Occidentale. Hommages à Michel Bats, Hyères-les-Palmiers 2011, en prensa.

Barr-Sharrar, B. 2008: The Derveni Krater. Masterpiece of Classical Greek Metalwork, Ancient Art and Architecture in Context 1, Princeton.

Benassai, R. 1995: "Sui dinoi bronzei campani”, Studi sulla Campania preromana, serie 3, vol. II, Roma, 157-205.

Benassai, R. 2002: "Un cinerario campano a Perugia", Annali Faina 9, 523-540.

Bianco, S. 2002: "Corredo di bronzi da Guardia Perticara (Potenza), località San Vito, tomba 218 (scavi 6/10/1997)", A. Giumlia-Mair, M. Rubinich, (ed.): Le arti di Efesto. Capolavori in metallo dalla Magna Grecia, Trieste, 220.

Bieg, G. 2002: Hochdorf V. Der Bronzekessel aus dem späthallstattzeitlichen Fürstengrab von Eberdingen-Hochdorf (Kr. Ludwigsburg). Griechische Stabdreifüße und Bronzekessel der archaischen
Zeit mit figürlichem Schmuck. Mit Beiträgen von Peter Eichhorn und Werner Gauer, Stuttgart.

Blanco, A. 1965: "Ein Figürlich Verzierter bronzener Oinochoenhenkel aus Málaga", Madrider Mitteilungen 6, 84-90.

Blanco Freijeiro, A. y Corzo Sánchez, R. 1983: "Monte Algaida. Un santuario púnico en la desembocadura del Guadalquivir", Historia 16, 123-128.

Blázquez, J. M. 1960: "Recipientes de bronce del Museo Nacional De Madrid", Archivo Español de Arqueología 33, 197-210.

Blázquez 1975: Tartesos y los origenes de la colonización fenicia en occidente, Salamanca.

Botto, M. y Vives Ferrándiz, J. 2006: "Importazioni etrusche tra le Baleari e la Penisola Iberica (VIII - prima metà del VII sec. a.C.)", Annali Faina 13: 117-196.

Bouloumié, B. 1985: "Les vases de bronze etrusques et leur diffusion hors d'Italie", Il commercio etrusco arcaico. Atti dell'incontro di studio, Quaderni del Centro di Studio per l'Archeologia Etrusco-Italica, 9, Roma, 167-178.

Boulomié, B. 1986: "Vases de bronze étrusques du service du vin", J. Swaddling (ed.), Italian Iron Age Artefacts in the British Museum. Papers of the Sixth British Museum Classical Colloquium, London, 63-79.

Brandherm, D. 2007: "Las espadas del Bronce Final en la Peninsula Ibérica y Baleares”, Prähistorische Bronzefunde IV, 16 Franz Steiner, Stuttgart.

Brommer, F. y Krumme, M. 1989: Kunst und Archäologie. Die Sammlung Brommer, Berlin.

Brown, W.L. 1960: The Etruscan lion, Oxford.

Bruni, S. 2006: "Ullastret e il pittore di Micali: Appunti sulla produzione di kylikes nell'Etruria arcaica", Studi Etruschi 72, 97-116.

Celestino, S. 1991: "Cancho Roano, un complejo urbano orientalizante en Zalamea de la Serena (Badajoz)", J. Remesal, y J. O. Musso (eds.), La presencia de material etrusco en la Península Ibérica, Barcelona, 439-455.

Celestino, S. y Zulueta, P. 2003: "Los bronces de Cancho Roano", S. Celestino (ed.), Cancho Roano IX. Los materiales arqueológicos II, Mérida, 11123.

Colonna, G. 2006: "Il commercio etrusco arcaico vent'anni dopo (e la sua estensione fino a Tartesso)", Annali Faina 13: 9-28.

Corzo, R. 1991: "Piezas etruscas del santuario de la Algaida (Sanlúcar de Barrameda, Cádiz)", J. Remesal y O. Musso, (eds.), La presencia de material etrusco en la Península Ibérica, Barcelona, 399-411. 
Corzo, R. 2000: "El santuario de la Algaida (Sanlúcar de Barrameda, Cádiz) y la formación de sus talleres artesanales”, B. Costa y J. Fernández (eds.), Santuarios fenicio-púnicos en Iberia y su influencia en los cultos indígenas, XIV Jornadas de Arqueología Fenicio- Púnica, Ibiza y Formentera 147-183.

Croissant, F. y Rouillard, P. 1996: "Le Problème de l'art gréco-ibère: état de la question", R. Olmos y P. Rouillard, (eds.), Formes archaïques et Arts ibériques, Formas arcaicas y arte ibérico, Madrid, 55-66.

Dentzer, J. M. 1982: Le motif du banquet couché dans le Proche-orient et le monde grec du VIIe au IVe siècle avant J.-C., Roma.

Dontas, G. 1969: “ $\Lambda \mathrm{AK} \Omega \mathrm{N} \mathrm{K} \Omega \mathrm{MA} \Sigma \mathrm{TH} \Sigma$ ”, Bulletin de Correspondance Hellénique 93/1, 39-55.

Fernández, F. 1972: "Objetos de origen exótico en El Raso de la Candeleda (Ávila)", Trabajos de Prehistoria 29, 273-290.

Fernández, F. 1991: “Un aplique de bronce en El Raso de Candeleda (Ávila)", J. Remesal y O. Musso (eds.), La presencia de material etrusco en la Península Ibérica, Barcelona, 615-617.

Fernández-Miranda, M., Deamos, M. B., Cerdá i Juan, D. y Nicolas, J de. 1979: El fondeadero de Cales Coves (Alayor, Menorca), Madrid.

García y Bellido, A. 1945: "De arqueología Balear. Algunos bronces mallorquinos", Archivo Español de Arqueología 18, 284-304.

García y Bellido 1948: Hispania Graeca, Barcelona.

García Cano, J. M. 1991: "El comercio arcaico en Murcia", J. Remesal y O. Musso (eds.): La presencia de material etrusco en la Península Ibérica, Barcelona, 369-382.

Gercke, W. B. 1996: Etruskische Kunst im KestnerMuseum Hannover, Hannover.

Gjødesen, M. 1944: "Bronze paterae with antropomorphous Handles", Acta Arch. Kobenhavn 15, 101-187.

Graells, R. 2006: "La vaixella metàl-lica protohistòrica a Catalunya (s. viI-v a.C.)", Cypsela 16, 195211.

Graells, R. 2006-2007: "Los prótomos de caldero de tipo oriental en la Península Ibérica: aproximación al problema y valoración", R. Graells (ed.), El valor social i comercial de la vaixella metàl-lica en el Mediterrani centre-occidental durant la protohistòria, Revista d'Arqueologia de Ponent 16-17, 292-299.

Graells, R. 2007: “El kyathos de la Cala Sant Vicenç y las producciones de vajilla metálica en Campania durante época arcaica: el ejemplo de los kyathoi con mango horizontal", Empúries 55, 95122.

Graells, R. 2008a: "De la Campània a la Cala Sant Vicenç: el kyathos reparat", X. Nieto y M. Santos (coords.), El Vaixell grec arcaic de la Cala Sant Vicenç, Monografies del CASC 7, 223-232.

Graells, R. 2008b: "Vasos de bronce con asas 'a kouroi' en el occidente arcaico: a la luz de un nuevo ejemplar procedente de Cuenca", Archivo Español de Arqueologia 81, 201-212.

Graells, R. 2010: Las tumbas con importaciones y la recepción del Mediterráneo en el nordeste de la Península Ibérica (ss. VII-VI a.C.), Revista d'Arqueologia de Ponent Serie Extra 1, Lleida.

Graells, R. 2011: "Un Manico di patera arcaica Gjødesen-IIA trovato a Maiorca", Siris, Rivista della Scuola di Specializzazione in Archeologia di Matera 10 (2009), 1-5.

Graells, R. e.p.: "The etruscans in the Iberian peninsula", A. Naso (ed.), Etruscology, New York, ed. De Gruyter, en prensa.

Graells, R. y Armada, X. L. 2011: "La 'tumba del soporte' de Calaceite a partir de los materiales del Musée des Antiquités Nationales de Saint Germain-en-Laye", Studi Etruschi 74, 17-37.

Gran-Aymerich, J. 1986: "Vases métalliques et céramiques dans le contexte étrusco-italique archaïque", J. Swaddling (ed.), Italian Iron Age Artefacts in the British Museum. Papers of the Sixth British Museum Classical Colloquium, London, 43-46.

Gran Aymerich, J. 2006: "Les étrusques et l'extrême occident $\left(\mathrm{VII}^{\mathrm{e}}-\mathrm{V}^{\mathrm{e}}\right.$ siècle av. J.C.): regards sur l'isthme gaulois et la Péninsule Ibèrique", Annali Faina 13, 253-283.

Gran Aymerich, J. 2010: "Gli Etruschi fuori d'Etruria: dons et offrandes étrusques en Mediterranée occidentale et dans l'Ouest de l'Europe", M. Gleba y H. Becker (eds.), Votives, Places, Rituals in Etruscan Religion. Studies in Honor of Jean MacIntosh Turfa, Brill, 15-41.

Guggisberg, M. 2005: "Bronzestatuette eines Tänzers aus der Umgebung von Ehringen, Gemeinde Wallerstein", Prähistorische Zeitschrift 80, 223235.

Haynes, S. 1985: Etruscan bronzes, London.

Herfort-Koch, M. 1986: Arcaische Bronzeplastik Lakoniens, Boreas 4, Münster.

Hill, D. K. 1949: Catalogue of Classical bronze sculpture in the Walters Art Gallery, Baltimore.

Hill, D. K. 1958: "A Class of Bronze Handles of the Archaic and Classical Periods", American Journal of Archaeology 62.2, 193-201.

Jurgeit, F. 1999: Die etruskischen und italischen 
Bronzen sowie Gegenstände aus Eisen, Blei und Leder im Badischen Landesmuseum Karlsruhe, Pisa-Roma.

Kukahn, E. 1969: "Una aplicación de una krátera de bronce, griega”, CNA X, Mahón, 440- 441.

Kunze, M. 2007: Griechische und römische Bronzen. Meisterwerke antiker Bronzen und Metallarbeiten aus der Sammlung Borowsky, Ruhpolding.

Llobregat, E. 1982: "Iberia y Etruria. Notas para una revisión de las relaciones", Lucentum 1, 71-91.

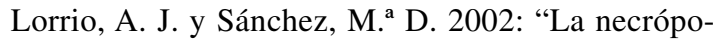
lis romana de Haza del Arca y el santuario del Deus Aironis en la Fuente Redonda (Uclés, Cuenca)", Iberia: Revista de la Antigüedad 5, 161193.

Marcos, A. y Ruiz, D. 2005: "Las necropolis de Poble Nou y de Casetes, dos yacimientos ibericos excepcionales de la Vila Joiosa", J.M.G. León y J. Espinosa, J. (ed.), las Jornadas sobre la actualidad del patrimonio arqueológico y etnográfico de la Marina Baixa, Altea, 73-80.

Mariné, M. 2011: Cien piezas del Museo de Ávila, Junta de Castilla y Léon.

Marzoli, D. 1991: "Alcune considerazioni su ritrovamenti di brocchette etrusche", J. Remesal y O. Musso (eds.), La presencia de material etrusco en la Península Ibérica, Barcelona, 215-218.

Micozzi, M. 1993: "Il giovane 'egineta' di Caere e il suo contesto", Prospettiva 71, 2-11.

Mitten, D. G. y Doeringer, S. F. 1967: Master bronzes from the classical world, Mainz.

Molinero-Pérez, A. 1958: "Un bronce etrusco en El Raso (Candeleda, Ávila)", Archivo Español de Arqueología 31, 175-177.

Muscarella, O. 1974: Ancient Art: the Norbert Schimmel collection, New York.

Naso, A. 2003: I bronzi etruschi e italici del RömischGermanisches Zentralmuseum, Mainz.

Naso 2006a: "Anathemata etruschi nel Mediterraneo orientale", Annali Faina 13, 351-416.

Naso 2006b: "Etruscan and Italic finds in North Africa, 7th - 2nd century B.C.", A. Villing y U. Schlotzhauer (eds.), Naukratis: Greek Diversity in Egypt. Studies on East Greek Pottery and Exchange in the Eastern Mediterranean, London, 187-198.

Neugebauer, K. A. 1943: "Archaische Vulcenter Bronzen", Jarhbuch des Deutschen Archäologischen Instituts 58, 206-278.

Oliva, M. 1976: "Excavaciones arqueológicas en el yacimiento prerromano de Ullastret, Bajo Ampurdán (Gerona). Propiedad de la Excma. diputación provincial", Noticiario Arqueológico Hispánico 4, 733-799.
Olmos, R. 1977: "El Sileno Simposiasta de Capilla (Badajoz)", Trabajos de Prehistoria 34, 371-388.

Olmos, R. 1983: "El centauro de Royos y el centauro en el mundo ibérico", Homenaje al Profesor Martín Almagro Basch, Vol. 2, 377-388.

Olmos, R. 2000a: "43. Centauro de Royos", P. Cabrera y C. Sánchez (eds.), Los griegos en España. Tras las huellas de Heracles, Madrid, 269.

Olmos, R. 2000b: "44. Sátiro itifálico del Llano de Consolación”, P. Cabrera y C. Sánchez, (eds.), Los griegos en España. Tras las huellas de Heracles, Madrid, 270.

Olmos, R. y Sánchez, C. 1995: "Usos e ideología del vino en las imágenes de la Hispania prerromana", S. Celestino (ed.), Arqueología del vino. Los orígenes del vino en Occidente, Jerez de la Frontera, 105-136.

Olmos, R. y Picazo, M. 1979: “Zum Handel griechischen Vasen und Bronzen auf der Iberischen Halbinsel", Madrider Mitteilungen 20, 184-201.

Ortiz, G. 1996: Faszination der Antike: the George Ortiz Collection; Staatliche Museen Berlin, Preussischer Kulturbesitz, Altes Museum 7, Bern.

Pozo, S. 2003: "Recipientes y vajilla metálica de época pre-romana (fenicia, griega y etrusca) del sur de la Península Ibérica", Antiquitas 15, 5-50.

Prados, L. 1997: "Los bronces figurados como bienes de prestigio", R. Olmos y P. Rouillard (eds.), Formes archä̈ques et Arts ibériques, Formas arcaicas y arte ibérico, Madrid, 83-95.

Richardson, E. H. 1983: Etruscan votive bronzes: geometric, orientalizing, archaic, Mainz.

Riis, P. J. 1938: "From the Collection of the $N y$ Carlsberg”, Glyptothek 2, Copenhagen.

Riis, P. J. 1959: "The Danish Bronze vessels of greek, early campanian, and Etruscan manufactures", Acta Archaeologica 30, 1-50.

Riis, P. J. 1998: Vulcentia vetustiora. A study of Archaic Vulcian Bronzes, Copenhagen.

Rodero, A. 2000: "45. Sileno simposiasta de Capilla”, P. Cabrera y C. Sánchez (eds.): Los griegos en España. Tras las huellas de Heracles, Madrid, 271.

Rolley, C. 1982: Les vases de bronze de l'archaïsme récent en Grande-Grèce, Napoli.

Sanahuja, M. 1971: "Noticia sobre un aplique stamnos-sítula procedente de Ullestret", Pyrenae 7, 162-164.

Sanmartí, E. 1993: “Ampurias”, Historia 16. Cuadernos del Arte Español 93, Madrid, 3-31.

Sanmartí, J., Asensio, D. y Martín, A. 2006: "Etruscan imports in the indigenous sites of Catalonia", Da Genova ad Ampurias. Atti del XXIV Convegno di Studi etruschi e italici, Pisa, 193-202. 
Stibbe, C. M. 1997: "Archaic bronze palmette", Bulletin Antieke Beschaving 72, 37-64.

Stibbe, C. M. 2003: Trebenishte. The fortunes of an unusual excavation, Roma.

Tarditi, Ch. 1996: Vasi di bronzo in area apula. Produzioni greche e italiche di età arcaica e classica, Lecce.

Torelli, M. 1986: "Dialogues sur le trépied étrusque", Dialogues Histoire Ancienne 12, 120- 121.

Vives-Ferrándiz, J. 2006-2007: "La vida social de la vajilla etrusca en el este de la Península Ibérica. Notas para un debate", R. Graells (ed.), El valor social i comercial de la vaixella metàl-lica en el Mediterrani centre-occidental durant la protohistòria, Revista d'Arqueologia de Ponent 16-17, 318-324.

Vives-Ferrándiz, J. 2007: "A propósito de un infundibulum etrusco hallado en aguas de la bahía de
Xàbia (Alacant)", Madrider Mitteilungen 48, 153173.

Vocotopoulou, J. 1975: "Le trésor de vases de bronze de Votonosi", BCH 99, 729-788.

Von Bothmer, D. 1961: Ancient art from New York private collections: catalogue of an exhibition held at the Metropolitan Museum of Art, New York.

Walters, H. B. 1899: Catalogue of the bronzes, Greek, Roman, and Etruscan, in the Department of Greek and Roman Antiquities, British Museum, London.

Weber, Th. 1983: Bronzekannen: Studien zu ausgewählten archaischen und klassischen Oinochoenformen aus Metall in Griechenland und Etrurien, Frankfurt.

Weber-Lehmann, C. 1985: "Spätarchaische Gelagebilder in Tarquinia", Römische Mitteilungen 92, 19-44.

Recibido: 25-10-2011

Aceptado: 11-05-2012 